\title{
Surface Passivation Effect by Fluorine Plasma Treatment on ZnO for Efficiency and Lifetime Improvement of Inverted Polymer Solar Cells
}

Ermioni Polydorou, ${ }^{1,2}$ Angelos Zeniou, ${ }^{1}$ Dimitris Tsikritzis, ${ }^{3}$ Anastasia Soultati, ${ }^{1,4}$ Ilias Sakellis, ${ }^{1,5}$ Spyros Gardelis, ${ }^{5}$ Theodoros Papadopoulos, ${ }^{6}$ Joe Briscoe, ${ }^{7}$ Leonidas C. Palilis, ${ }^{2}$ Stella Kennou, ${ }^{3}$ Evangelos Gogolides, ${ }^{1}$ Panagiotis Argitis, ${ }^{1}$ Dimitris Davazoglou, ${ }^{1}$ Maria Vasilopoulou ${ }^{1, *}$

${ }^{1}$ Institute of Nanoscience and Nanotechnology, National Center for Scientific Research Demokritos, 15310, Aghia Paraskevi, Attiki, Greece

${ }^{2}$ Department of Physics, University of Patras, 26504 Patras, Greece

${ }^{3}$ Department of Chemical Engineering, University of Patras, 26500 Patras, Greece

${ }^{4}$ Department of Chemical Engineering, National Technical University of Athens, 15780, Athens, Greece ${ }^{5}$ Physics Department, Solid State Physics Section, University of Athens Panepistimioupolis, GR, 15784 Athens, Greece

${ }^{6}$ Department of Natural Sciences, University of Chester, Thornton Science Park, CH2 4NU, Chester, U. K. ${ }^{7}$ Materials Research Institute, School of Engineering and Materials, Queen Mary University of London, $U . K$. *email: m.vasilopoulou@inn.demokritos.gr

\begin{abstract}
Zinc oxide $(\mathrm{ZnO})$ is an important material for polymer solar cells (PSCs) where the characteristics of the interface can dominate both the efficiency and lifetime of the device. In this work we study the effect of fluorine $\left(\mathrm{SF}_{6}\right)$ plasma surface treatment of $\mathrm{ZnO}$ films on the performance of PSCs with an inverted structure. The interaction between fluorine species present in the $\mathrm{SF}_{6}$ plasma and the $\mathrm{ZnO}$ surface is also investigated in detail. We get fundamental insights into the passivation effect of fluorine by analyzing our experimental results and theoretical calculations and we propose a mechanism according to which a fluorine atom substitutes an oxygen atom or occupies an oxygen vacancy site eliminating an electron trap while it may also attract
\end{abstract}


hydrogen atoms thus favoring hydrogen doping. These multiple fluorine roles can reduce both the recombination losses and the electron extraction barrier at the $\mathrm{ZnO} /$ fullerene interface improving the selectivity of the cathode contact. Therefore, the fabricated devices using the fluorine plasma treated $\mathrm{ZnO}$ show high efficiency and stable characteristics, irrespective of the donor:acceptor combinations in the photoactive blend. Inverted polymer solar cells, consisting of the $\mathrm{P} 3 \mathrm{HT}: \mathrm{PC}_{71} \mathrm{BM}$ blend, exhibited increased lifetime and high power conversion efficiency (PCE) of $4.6 \%$, while the ones with the PCDTBT:PC ${ }_{71} \mathrm{BM}$ blend exhibited a PCE of 6.9\%. Our champion devices with the PTB7:PC ${ }_{71} \mathrm{BM}$ blends reached a high PCE of $8.0 \%$ and simultaneously showed exceptional environmental stability when using the fluorine passivated $\mathrm{ZnO}$ cathode interlayers.

Keywords: Polymer Solar Cells, Fluorine Plasma, ZnO, Surface Defect Passivation, Reduced Work Function.

\section{Introduction}

Harnessing abundant and renewable solar energy has been recognized as a promising way to address the world's quickly growing energy consumption and the increasing concerns about gas emissions coming from fossil fuels. Several approaches have been proposed and studied extensively to harvest solar energy; among them polymer solar cells (PSCs) based on bulk-heterojunctions (BHJs) consisting of polymer donors and fullerene acceptors have attracted extensive investigation as a potential alternative to conventional cells, mainly due to their inherent advantages of being low-cost and compatible with large area flexible substrates and solution-based processing techniques. ${ }^{1-6}$ The state of the art power conversion efficiencies (PCEs) of single junction PSCs exceeding $9 \%{ }^{7-9}$ while efficiencies higher than $11 \%$ have been achieved in small area tandem cells, ${ }^{10-13}$ which promises a bright future for the commercialization of such devices. To achieve higher power conversion efficiencies in PSCs, appropriate interfacial engineering based on suitable materials and processes has been identified as an essential approach for forming anode and cathode contacts of high quality, so as to optimize the hole and electron transport and collection. The electronic and structural 
properties of interfacial materials are of key relevance to the performance of PSC devices. Consequently, fundamental insight into interface engineering is of high priority for such systems.

Zinc oxide $(\mathrm{ZnO})$ has been recognized as the most extensively investigated cathode interfacial layer (CIL), mainly due to its suitable energy levels, high electron mobility, good transparency, environment stability and low cost. ${ }^{14-25}$ The energy levels of $\mathrm{ZnO}$ (conduction band bottom and valence band top) are at around -4.4 $\mathrm{eV}$ and $-7.8 \mathrm{eV}$, respectively; such band positions allow $\mathrm{ZnO}$ to function well for electron collection and hole blocking. Another advantage of $\mathrm{ZnO}$ as the CIL material is that it can be easily processed via a solution method with subsequent thermal treatment at relatively low temperatures. This makes the $\mathrm{ZnO}$ fully compatible with all solution fabrication on flexible plastic substrates, which is the predominant advantage of polymer solar cells. However, the presence of defects on the surfaces (and also at grain boundaries in the bulk) of $\mathrm{ZnO}$ films may result in significant charge recombination rates thus having a pronounced effect on the device performance. ${ }^{26-28}$ Especially, the solution processing of $\mathrm{ZnO}$ films often leads to a high density of surface defects, such as oxygen vacancies $\left(\mathrm{V}_{\mathrm{O}}\right)$ (or zinc dangling bonds) and zinc vacancies $\left(\mathrm{V}_{\mathrm{Zn}}\right)$ (or oxygen dangling bonds). ${ }^{29-31}$ Such surface defects can act as recombination centers for photogenerated charge carriers, decreasing the photocurrent and power conversion efficiency as well as the device lifetime. Hence, passivation of defects states at interfaces between the $\mathrm{ZnO}$ CILs and the photoactive blends are highly desirable and essential to achieve high PCE and adequate lifetime of PSCs. In this regard, many studies have focused on engineering the surface of $\mathrm{ZnO}$ films through improving the interfacial electrical properties, better aligning energy-level and controlling the surface energy. Among the most efficient methods to modify the $\mathrm{ZnO}$ surface are the ultraviolet (UV) or UV-ozone treatment, ${ }^{32-37}$ and the incorporation of a surface modification interlayer, such as a coordination polymer ${ }^{38,39}$ or a self-assembled monolayer (SAM). ${ }^{40-44}$ However, UV treatment may cause severe degradation of the device lifetime whereas the insulating properties of coordination polymers results in a trade-off between effective passivation and charge transport. In addition, the fabrication of large-area, compact and dense SAMs, which are resistant to subsequent processing procedures, is still challenging. In others strategies, functionalized or crosslinked fullerene derivatives were used to modify the surface of $\mathrm{ZnO}$ layer, ${ }^{45-46}$ while ethanedithiol treatment also effectively passivated the surface defects in $\mathrm{ZnO}$ film thus reducing the charge recombination and improving the 
device performance. ${ }^{47}$ Doping is also an efficient way to passivate surface defects and simultaneously enhance the conductivity of $\mathrm{ZnO}$. Through doping with group-II or group-III elements, an increase in the electrical conductivity of $\mathrm{ZnO}$ and, consequently, in the photovoltaic performance of PSCs with an inverted structure has been observed. ${ }^{48-52}$ Besides the metal and also nitrogen doping which has also been reported to tune the properties of the zinc oxide surface, ${ }^{53}$ our group and others recently introduced the beneficial surface modification of $\mathrm{ZnO}$ by using a hydrogen $(\mathrm{H})$ plasma treatment for efficient inverted PSCs. ${ }^{54,55}$ Plasma surface treatment is a process that alters the surface energy of many materials so as to improve the bonding characteristics. In our previous work it was found that $\mathrm{H}$ plasma treatment altered the surface properties of $\mathrm{ZnO}$ films, in particular the wetting of the photoactive layer, while it also reduced surface roughness and induced significant changes in the nanomorphology/crystallinity of the photoactive blend, which was deposited on top of the $\mathrm{ZnO}$ surface, allowing efficient charge generation and extraction. In addition, a reduction in the work function of $\mathrm{ZnO}$ followed by a decreased energy barrier for electron extraction from fullerene acceptor was evident.

In this work we study the effect of the $\mathrm{SF}_{6}$ plasma treatment of $\mathrm{ZnO}$ on the performance of PSCs with an inverted structure while we also reveal the details of the interaction between fluorine $(\mathrm{F})$ species (atoms, radicals) produced by the dissociation of the $\mathrm{SF}_{6}$ plasma and the $\mathrm{ZnO}$ surface. Fluorine has been recognized as one of the most effective n-type dopants and passivation elements for the fabrication of $\mathrm{ZnO}$-based transparent conductive oxides, ${ }^{56-58}$ while recently it was found that fluorine-containing $\mathrm{ZnO}$ films allow the fabrication of thin film transistors which exhibit high field effect mobility with adequate gate bias stability. ${ }^{59,60}$ However, its beneficial use in passivating $\mathrm{ZnO}$ surface defects and/or enhance its n-type conductivity for application in organic optoelectronics has not been demonstrated up to now. Here we demonstrate that a mild $\mathrm{SF}_{6}$ plasma post deposition treatment of $\mathrm{ZnO}$ results in significant enhancement of the efficiency and lifetime of inverted PSCs through effective passivation of surface defects as evidenced by the suppression of the visible emission and the enhancement of the near-band-edge (NBE) photoluminescence of the $\mathrm{ZnO}$ films. We get fundamental insights into the passivation mechanism by analyzing our experimental results and theoretical calculations and reveal that fluorine may substitute oxygen atoms and/or oxygen vacancies (zinc dangling bonds) sites in the $\mathrm{ZnO}$ atomic structure. In addition, 
because of their high electronegativity, fluorine anions bonded to $\mathrm{ZnO}$ surface may attract hydrogen atoms favoring the formation of intermolecular hydrogen bonds such as F...HO, resulting in the passivation of surface $\mathrm{O}$ dangling bonds. The occupation of an $\mathrm{O}$ vacancy by an $\mathrm{F}$ atom and the reduction of the amount of oxygen dangling bonds have a pronounced effect on the device performance by significantly reducing the density of trap states, which are located inside the bandgap of $\mathrm{ZnO}$ and nearly aligned with the highest occupied molecular orbital (HOMO) level of most polymer donors acting as recombination centers for the photogenerated holes. Consequently, the recombination losses at the $\mathrm{ZnO}$ /photoactive blend interface are significantly suppressed giving rise to high devices photocurrents. Moreover, a reduced work function of the fluorine plasma treated $\mathrm{ZnO}$ layer was proven beneficial for obtaining improved open circuit voltages in the device structures. As a result, inverted devices based on photoactive layers consisting of poly(3hexylthiophene) (P3HT):[6,6]-phenyl C71butyric acid methyl ester $\left(\mathrm{PC}_{71} \mathrm{BM}\right)$ and poly[N-9'-heptadecanyl2,7-carbazole-alt-5,5-(4',7'-di-2-thienyl-2',1',3'-benzothiadiazole)] (PCDTBT):PC ${ }_{71} \mathrm{BM}$ blends exhibited excellent performance and stability characteristics with PCE values of up to $4.6 \%$ and $6.9 \%$, respectively, whereas our highest performing poly[[4,8-bis[(2-ethylhexyl)oxy]benzo[1,2-b:4,5-b']dithiophene-2,6-diyl][3fluoro-2-[(2-ethylhexyl) carbonyl]thieno[3,4-b]thiophenediyl]] (PTB7):PC ${ }_{71} \mathrm{BM}$ based device reached the high PCE of $8.0 \%$ while also presented significantly enhanced lifetime when using the $\mathrm{SF}_{6}$ treated $\mathrm{ZnO}$ bottom cathode interlayer. Therefore, the fluorine plasma passivation of $\mathrm{ZnO}$ is effective to improve both the efficiency and lifetime of different kind $\mathrm{ZnO}$ films through effective passivation of their surface defects for their application in high performing and stable PSC devices.

\section{Results and discussion}

2.1 Influence of Fluorine Plasma Treatment on the Surface Properties of $\mathbf{Z n O}$. The $40 \mathrm{~nm}$ thick solution processed $\mathrm{ZnO}$ films were grown using a sol-gel deposition method. The room-temperature photoluminescence (PL) spectra of the as-grown $\mathrm{ZnO}$ films present a relatively sharp UV (the so-called near-band-edge, NBE) emission around $380 \mathrm{~nm}(3.26 \mathrm{eV})$ and a broad emission within the visible range (Figure 1a). The former is due to free exciton emission since the bound excitons are usually thermally ionized at room temperature, ${ }^{61}$ while the latter is usually attributed to structure defects such as oxygen $\left(\mathrm{V}_{\mathrm{O}}\right)$ 
and zinc vacancies $\left(\mathrm{V}_{\mathrm{Zn}}\right)$ (see also Figure $\mathrm{S} 1$, Supporting Information). ${ }^{62,63}$ The $\mathrm{V}_{\mathrm{O}}$ energy states are partially occupied and are typically located at about $0.8-1.0 \mathrm{eV}$ below the bottom of the conduction band, ${ }^{64,65}$ acting thus as trap states for the photogenerated charge (especially for the photogenerated holes, as will be discussed below) leading to higher recombination rates. ${ }^{66}$ After surface treatment with a mild (in order to avoid etching of the $\mathrm{ZnO}$ surface) $\mathrm{SF}_{6}$ plasma for $5 \mathrm{~min}$ (the optimized plasma process conditions in order to obtained best device performance are described in the experimental section) it is found that visible (defect) emission is significantly suppressed while the NBE is greatly enhanced compared to that of the as-grown $\mathrm{ZnO}$ films. The reduction of the visible emission can be attributed to the passivation of surface states such as dangling bonds and oxygen and zinc vacancies with fluorine plasma treatment. However, the fact that visible emission is not completely quenched may derive from defects and grain boundaries present in the bulk material which could not be passivated by the mild plasma treatment (since fluorine species coming from the dissociation of $\mathrm{SF}_{6}$ molecules are present only within few nanometers from the $\mathrm{ZnO}$ surface). However, the surface defect and nonradiative recombination centers can be significantly passivated by F, resulting in both the significant suppression in visible and the enhancement in NBE emission in the $\mathrm{SF}_{6}$ treated $\mathrm{ZnO}$ sample (termed hereafter as $\mathrm{F}-\mathrm{ZnO}$ ). Moreover, additional radiative recombination emission can be caused by $\mathrm{F}$ doping (and possibly by $\mathrm{H}$ doping, as explained below) in the near surface region, which would contribute to the enhanced NBE. ${ }^{67}$ Thus, by $\mathrm{SF}_{6}$ plasma treatment both surface passivation effect and probably doping of the near surface region may be responsible for the observed changes in the PL spectra.

The crystal structures of the as-grown and the $\mathrm{SF}_{6}$ treated $\mathrm{ZnO}$ films deposited on $\mathrm{Si}$ substrates were analyzed by measuring the X-ray diffraction (XRD) patterns shown in Figure 1b. The UV-vis transmission and absorption spectra of the same films deposited on quartz substrates are presented in Figure S2. Both films exhibit a single diffraction peak at $2 \theta$ angle of 34.30 degrees which was indexed as the (002) plane in agreement with the standard diffraction pattern (JCPDS 36-1451) of a hexagonal wurtzite $\mathrm{ZnO}$ structure. ${ }^{68}$ It is worth noting that the recorded (002) preferred orientation implies a highly textured structure of the films, with the c-axis oriented perpendicular to the substrate (Figure 1c). The full-width at half-maximum (FWHM) of (002) peaks was nearly identical indicating a similar grain size in both films. The surface morphology of $\mathrm{ZnO}$ and $\mathrm{F}-\mathrm{ZnO}$ thin films was investigated by atomic force microscopy (AFM), and the resulting images 
are shown in Figures $1 \mathrm{~d}$ and 1e, respectively. The as-grown and $\mathrm{SF}_{6}$ treated $\mathrm{ZnO}$ films exhibited a surface structure consisting of columnar grains of different sizes. The columnar morphologies are regarded as c-axis growth orientations. ${ }^{68}$ Columnar grains increased in size after fluorine plasma treatment of ZnO. This morphological change might be the result of the F surface passivation, which reduces the density of grain boundaries through saturating the surface dangling bonds, and is not influenced by the difference in processing as films were grown under identical conditions. However, a similar conclusion was not derived from the XRD data since there was no change in the FWHM of those films. We anticipated that this is because the diffusion of $\mathrm{F}$ species coming from the $\mathrm{SF}_{6}$ plasma is limited within only a few nanometers from the film's surface and therefore no changes were detected with XRD. An additional explanation for the similarity of the XRD patterns is that changes in the peak position resulting from lattice distortion with $\mathrm{F}$ doping were not observed because the ionic radius of $\mathrm{F}\left(1.34^{\circ} \mathrm{A}\right)$ is quite similar to that of $\mathrm{O}\left(1.39^{\circ} \mathrm{A}\right)$ and therefore no structural changes are expected when F atoms fill oxygen and/or oxygen defect sites.

There are limitations of the analysis based on the XRD patterns and surface morphologies of the films in fully unravelling the passivation effect of $\mathrm{SF}_{6}$ plasma on the surface of $\mathrm{ZnO}$. Thus, an $\mathrm{X}$-ray photoelectron spectroscopy (XPS) study was performed to better understand the surface passivation mechanism because the analysis depth in an XPS study covers the outer surface layers where the main effect of plasma treatment is expected. The XPS wide scans of the as-grown and fluorine plasma treated films are shown in Figure S3 and were used to determine the changes of the chemical states of the $\mathrm{ZnO}$ after plasma treatment. Figure $2 \mathrm{a}$ shows the $\mathrm{Zn} 2 \mathrm{p}_{3 / 2}$ XPS peak of the as-grown and the plasma treated samples. In the as-grown sample the $\mathrm{Zn}$ $2 \mathrm{p}_{3 / 2}$ peak appears at $1021.6 \mathrm{eV}$. After plasma treatment, the peak is shifted to $1022.3 \mathrm{eV}$; this $0.7 \mathrm{eV}$ shift shows that the chemical environment of the $\mathrm{Zn}$ is changed, maybe due to the formation of $\mathrm{Zn}-\mathrm{F}$ bonds causing the passivation of the $\mathrm{Zn}$ dangling bonds (and O vacancies) by F atoms. The XPS wide scans of both $\mathrm{ZnO}$ films (Figure S3) show that there are no sulfur atoms present on the surface of the plasma treated $\mathrm{ZnO}$ (Figure S4) which supports our argument that the only surface passivation element in the $\mathrm{SF}_{6}$ plasma treated sample is fluorine. In Figure $2 \mathrm{~b}$ the F 1 s core level peak appearing at $685.1 \mathrm{eV}$ is shown. This peak was assigned to the $\mathrm{Zn}-\mathrm{F}$ bond of the plasma treated sample. ${ }^{69-71}$ From the F1s and FKLL peaks the Auger parameter was calculated equal to $1340.4 \mathrm{eV}$, which also indicates the existence of $\mathrm{ZnF}_{2}$ in the near surface 
region of our $\mathrm{SF}_{6}$ plasma treated sample. ${ }^{72}$ The $\mathrm{O} 1 \mathrm{~s}$ core levels (Figures $2 \mathrm{c}$ and d) were deconvoluted into two different oxygen peaks at $530.6 \mathrm{eV}$ and $532.2 \mathrm{eV}$, which can be assigned to oxygen in the oxide lattice (oxygen bonded to metal atoms) and to hydroxyl groups, respectively. ${ }^{73}$ The area of the latter is increased in the plasma treated sample which indicates the formation of surface hydroxyl groups (as will be discussed below).

In order to explore the impact of fluorination on the $\mathrm{ZnO}$ surface (Figure S5 a), Density Functional Theory (DFT) calculations were carried out to investigate the modification of the surface electronic structure using the theoretical procedure described in the methodology section. Plotting the density of states (DOS) of the O-terminated $\mathrm{ZnO}(0002)$ surface (Figure 3a), we observe that states located $0.1 \mathrm{eV}$ below the valence band maximum (VBM) mainly consist of $\mathrm{O} 2 p$ levels with almost no contribution from $\mathrm{Zn}$ states. We also observe the appearance of sharp states in a range of energies from $-1.5 \mathrm{eV}$ up to $0.2 \mathrm{eV}\left(\mathrm{E}_{\mathrm{F}}=0 \mathrm{eV}\right)$, which involve contribution from $p$ and hybridized $d$ orbitals of the surface $\mathrm{O}$ atoms. This provides proof to support our hypothesis that oxygen unsaturated orbitals at the surface are mainly responsible for energy states appearing at the conduction band minimum (CBM). To investigate the effect of fluorination, we initially substitute $25 \%$ of surface oxygen atoms with fluorine atoms (Figure S5 b). Our calculations indicate that this process releases $-1.17 \mathrm{eV}$ of energy per substituted fluorine atom, making fluorination of the $\mathrm{ZnO}$ surface a favorable scenario. The calculated DOS (Figure 3b) show a reduction in unsaturated surface O $2 p$ states below the CBM. To investigate further the impact of fluorination on the surface electronic structure, we introduce full fluorination in our model (Figure $\mathrm{S} 6$ a), i.e. substitution of all $\mathrm{O}$ surface atoms by $\mathrm{F}$ atoms. Due to the presence of ambient $\mathrm{H}$ atoms during the experimental conditions, $\mathrm{H}$ atoms adsorbed on the surface are also incorporated; it was found that the adsorption energy per $\mathrm{H}$ atom is $-4.78 \mathrm{eV}$, which indicates strong tendency for bonding with fluorine. Figure 3c shows the calculated DOS for this case; we observe that all unsaturated surface $\mathrm{O} 2 p$ orbitals have vanished with $\mathrm{F} 2 p$ states being located at the VBM. The adsorbed $\mathrm{H}$ atoms contribute to the DOS profile mainly core $s$ states with minor contribution from hybridized $p$ states at $-5 \mathrm{eV}$ (Figure $\mathrm{S} 6 \mathrm{~b}$ ). Our calculations show that fluorination gives rise to effective passivation and suppression of unwanted surface oxygen states located below the CBM. 
To explain our experimental and theoretical results we propose the surface passivation mechanism presented in Figure 3d. As schematically illustrated, fluorine atoms can substitute oxygen or occupy oxygen vacancy sites in the $\mathrm{ZnO}$ atomic structure because fluorine and oxygen have similar ionic sizes. The substitution of an oxide oxygen atom by a $\mathrm{F}$ creates a free electron due to the difference in the electrovalence of fluorine $\left(\mathrm{F}^{-}\right)$ and oxygen $\left(\mathrm{O}^{2-}\right) .^{74}$ The generated free electrons could also enhance the conductivity of the near surface $\mathrm{ZnO}$ layers which is an additional benefit for the PSC performance. On the other hand, the occupation of an oxygen vacancy site by a fluorine atom reduces the density of intergap states of $\mathrm{ZnO}$, which act as hole recombination centers since their energetic position (about $0.8-1.0 \mathrm{eV}$ below the minimum of the conduction band, $\mathrm{CB}$ ) is nearly aligned with the HOMO of most polymer donors (about 5.0-5.5 eV). These dual roles of the fluorine substitution/doping (reduction of trap sites and generation of extra charge carriers) can facilitate both the surface passivation and, probably, the higher conductivity in the upper layers of $\mathrm{ZnO}$. In addition, in the fluorine-passivated (doped) oxide thin films, the fluorine ions that have the strongest electronegativity may also attract hydrogen atoms (which are present in ambient air) which bond to the nearest $\mathrm{O}$ dangling bonds forming intermolecular hydrogen bonds F...HO thus passivating these dangling bonds, as represented in Figure 3d. This could explain the increased amount of hydroxyl groups present in the O 1s XPS spectrum of the fluorine $\mathrm{ZnO}$ sample.

Figure 4 a shows the ultra-violet photoelectron spectroscopy (UPS) measurements taken in the as-grown and fluorine plasma treated $\mathrm{ZnO}$ samples. For the as-grown film, the valence band consists of two distinct features at $6.5 \mathrm{eV}$ and $10.8 \mathrm{eV}$ attributed to $\mathrm{O} 2 \mathrm{p}$ and $\mathrm{Zn} 3 \mathrm{~d}$ atomic orbitals, respectively. ${ }^{75,76}$ The valence band (VB) onset is at about $3.2 \mathrm{eV}$ from the Fermi level while the work function $\left(\mathrm{W}_{\mathrm{F}}\right)$ value, estimated from the high binding-energy cut-off, is $4.5 \mathrm{eV}$; therefore the top of the $\mathrm{VB}$ of the as-grown $\mathrm{ZnO}$ sample is estimated around $7.7 \mathrm{eV}$ with respect to the vacuum level. Taking into account the calculated optical band gap of $3.3 \mathrm{eV}$ (derived from UV-vis absorption measurements, Figure S2) the bottom of the CB is placed at 4.4 $\mathrm{eV}$ below vacuum. On the other hand, a pronounced shift of the characteristic peaks towards higher binding energies is observed in the UPS spectrum of the $\mathrm{SF}_{6}$ treated $\mathrm{ZnO}$ sample. The valence band onset is estimated around $3.7 \mathrm{eV}$ while the work function is reduced to $4.0 \mathrm{eV}$ resulting in a $\mathrm{VB}$ maximum of $7.7 \mathrm{eV}$ and a $\mathrm{CB}$ minimum of $4.4 \mathrm{eV}$ below vacuum (the energy gap of the $\mathrm{SF}_{6}$ treated sample remains unchanged, 
Figure S2). In addition, the $\mathrm{Zn} 3 \mathrm{~d}$ peak shifts to $11.5 \mathrm{eV}$ whereas the appearance of a new peak at $8.7 \mathrm{eV}$ is evident, which is attributed to $\mathrm{F} 2 \mathrm{p}$ atomic orbitals, supporting the formation of a $\mathrm{ZnF}_{2}$ layer on the film surface. $^{77,78} \mathrm{We}$ anticipate that the increase of the valence band onset and also of the position of $\mathrm{Zn} 3 \mathrm{~d}$ atomic orbitals (with respect to the Fermi level) is due to the de-trapping of electrons from surface states (like $\mathrm{O}$ vacancies and dangling bonds) which also results in a decrease of the surface work function of $\mathrm{ZnO}$. As discussed above, the surface and grain boundaries of $\mathrm{ZnO}$ are prone to electron trapping, which result in the formation of a space-charge region (depletion layer) and therefore in upward shift (band bending) of the $\mathrm{VB}, \mathrm{CB}$ and vacuum level in the as-grown sample, as illustrated in Figure $4 b^{79,80}$ Under $\mathrm{SF}_{6}$ plasma treatment, fluorine ions passivate defect levels in the zinc oxide surface and reduce (or even eliminate) the density of trapped electrons reducing significantly the width of the space-charge region and forcing the band edges to downward shift having as a net result the reduction of the work function in the $\mathrm{ZnO}$ surface (Figure $4 b)$.

2.3 Influence of Fluorine Plasma Treatment of $\mathrm{ZnO}$ on Polymer Solar Cells Performance. To find out whether the passivation of surface defects and the reduction of the $\mathrm{ZnO} \mathrm{W}_{\mathrm{F}}$ after $\mathrm{SF}_{6}$ treatment have a positive impact on the device performance, we applied our $\mathrm{ZnO}$ films as cathode interlayers in PSCs with the inverted structure of glass/FTO/ZnO /photoactive (BHJ) layer/ $\mathrm{MoO}_{\mathrm{x}} / \mathrm{Al}$, where the active layer is consisting of either P3HT:PC ${ }_{71} \mathrm{BM}$, PCDTBT:PC ${ }_{71} \mathrm{BM}$ or PTB7:PC ${ }_{71} \mathrm{BM}$ (Figure 5a). The energy level alignment of materials used in our devices is illustrated in Figure 5b. Note that the anode side of the devices was omitted for simplicity reasons. By using $\mathrm{SF}_{6}$ treated $\mathrm{ZnO}$ as cathode interlayer the defect states, which are nearly aligned with the HOMO level of the polymers donors acting as hole recombination centers, are passivated by fluorine atoms. In addition, the $0.5 \mathrm{eV}$ reduction of the $\mathrm{W}_{\mathrm{F}}$ of the fluorine passivated $\mathrm{ZnO}$ surface results in the formation of an electrical dipole with its positive pole pointing towards the photoactive layer, which is deposited on top of the $\mathrm{ZnO}$ surface. The interfacial dipole that contributes to the reduction of the $\mathrm{W}_{\mathrm{F}}$ of $\mathrm{ZnO}$ is directed away from the surface of $\mathrm{ZnO}$ thus favoring electron transport from the $\mathrm{CB}$ of the modified $\mathrm{ZnO}$ to the LUMO of PCBM as it considerably reduces the corresponding band offset. Furthermore, passivation of defect states would facilitate electron extraction and transfer at the modified $\mathrm{ZnO} / \mathrm{PCBM}$ interface. As a result, a $0.5 \mathrm{eV}$ downward shift of the vacuum level on the side of the 
photoactive layer is expected. This leads to reduction of the electron extraction barrier through perfect alignment between the bottom of the $\mathrm{CB}$ of $\mathrm{ZnO}$ and the lowest unoccupied molecular orbital (LUMO) of $\mathrm{PC}_{71} \mathrm{BM}$, facilitating electron extraction via the $\mathrm{CB}$ of $\mathrm{ZnO}$. Consequently, fluorine passivation of defect states in $\mathrm{ZnO}$ is expected to create trap free favorable paths for the photogenerated carriers which should be travelling towards and collected at the respective electrodes significantly enhancing the device performance. The current density-voltage (J-V) characteristics under 1.5 AM simulated solar illumination of PSCs using P3HT: $\mathrm{PC}_{71} \mathrm{BM}$ as the active layer and $\mathrm{ZnO}$ films as CILs are shown in Figure 6a. The dark J-V measurements and the external quantum efficiency (EQE) characteristics of the same devices are also shown in Figures $6 \mathrm{~b}$ and $\mathrm{c}$, respectively. The corresponding electrical output parameters of those devices are summarized in Table 1. The results show that upon $\mathrm{SF}_{6}$ plasma treatment, the devices exhibit higher PCEs reaching values up to $4.6 \%$ representing an efficiency enhancement of $60 \%$ compared with their counterparts having cathode interfaces consisting of the as-grown $\mathrm{ZnO}$ layers with the maximum obtained PCE of $2.9 \%$. Dark J-V curves show that fluorine plasma treatment significantly improved the selectivity of the cathodes. As shown in Figure 6b, the reverse saturation current for the devices with F-ZnO is greatly suppressed compared to the devices with $\mathrm{ZnO}$, while the former devices also exhibit higher currents in the forward direction and reduced series and increased shunt resistances (Table 1) verifying the overall higher quality of the diodes based on the fluorine passivated ZnO CILs. The decreased reverse saturation current of the devices with $\mathrm{F}-\mathrm{ZnO}$ layers compared to those with $\mathrm{ZnO}$, can partially explain the significant increase in the open circuit voltage $\left(\mathrm{V}_{\mathrm{oc}}\right)$ of the former devices whereas their reduced series resistance as well as their increased shunt resistance may explain the enhanced short-circuit current $\left(\mathrm{J}_{\mathrm{sc}}\right)$ and fill factor $(\mathrm{FF})$ obtained in those devices. In addition, significantly increased external quantum efficiency (EQE) values over the entire photoresponsive spectral range were observed in the F-ZnO based devices when compared with their counterparts based on the as-grown $\mathrm{ZnO}$. This enhancement in EQEs suggests that the photon-to-electron conversion processes are very efficient in the former devices and provide clear evidence for enhanced charge extraction/collection, attributed to a decrease in the electron extraction barrier and/or a decrease in recombination losses, as discussed above. Note that an enhancement in the charge generation efficiency of the device with the fluorine plasma $\mathrm{ZnO}$ as compared with the reference one due to better film 
nanomorphology in the former case was not supported by our data. In particular, we obtained absorption, $\mathrm{XRD}$ and $\mathrm{AFM}$ measurements on $\mathrm{P} 3 \mathrm{HT}: \mathrm{PC}_{71} \mathrm{BM}$ films with a thickness of $150 \mathrm{~nm}$ (similar to that used in the device structure) deposited on the as-grown and the F plasma treated $\mathrm{ZnO}$ layer. The results (Figures S7 and S8) evidenced nearly similar nanomorphologies of those films. In addition, we obtained absorption and AFM measurements in thin (30 nm thick) $\mathrm{P} 3 \mathrm{HT}: \mathrm{PC}_{71} \mathrm{BM}$ films in order to probe possible influence of the surface properties of $\mathrm{ZnO}$ underlayers in the nanomorphology near the interface. Once again, we obtained almost identical results (Figures S9 and S10), which is an indication that the alteration of surface energy of $\mathrm{ZnO}$ and also of the nanomorphology of the active blend on top of it could not be the main reason for such a significant enhancement in the photocurrent and EQE of the devices with the fluorine passivated CILs as was in the case of the devices with the $\mathrm{H}$ plasma treated $\mathrm{ZnO}$ layers. ${ }^{54}$ The above argument is also supported by the increase of the $\mathrm{ZnO}$ substrate hydrophilicity after $\mathrm{F}$ plasma treatment resulting in small degradation of the wetting of the photoactive blend as concluded from contact angle measurements taken in the as-grown and $\mathrm{SF}_{6}$ treated $\mathrm{ZnO}$ layers (Figure $\mathrm{S} 11$ ). However, the most hydrophilic F plasma-treated ZnO layer could favor the accumulation of fullerene on top of it which could be beneficial for the device operation. Remarkably, in addition to the significant efficiency enhancement, the ambient stability of the devices with the HZO layers is also significantly improved as shown in Figures 6d, e and f. For the non-encapsulated P3HT: $\mathrm{PC}_{71} \mathrm{BM}$ devices, the $\mathrm{J}_{\mathrm{sc}}, \mathrm{V}_{\mathrm{oc}}$ and $\mathrm{FF}$ retained more than $80 \%$ of their original values after being stored in dark and under ambient conditions for a period of 1500 hours (two months). In contrast, the corresponding values of the control devices with the $\mathrm{ZnO}$ layers decreases significantly over the same period after being stored under the same conditions. This significant increase in the ambient stability of the F- $\mathrm{ZnO}$ based devices may be attributed to the fluorine passivation of the surface defects and dangling bonds. In order to gain deeper understanding on the origin of the improved device performance, electron-only devices having the structure $\mathrm{FTO} / \mathrm{ZnO} / \mathrm{P} 3 \mathrm{HT}: \mathrm{PC}_{71} \mathrm{BM} / \mathrm{Al}$ were fabricated and measured to investigate their electron transport properties. Figure 7a shows the dark current density-voltage measurements for devices with as-grown and $\mathrm{SF}_{6}$ plasma treated $\mathrm{ZnO}$ layers. The device with the $\mathrm{ZnO}$ exhibits significantly lower (more than two orders of magnitude) current density as compared to the device with the plasma treated $\mathrm{ZnO}$ sample. This result reveals the superior electron transport characteristics of the latter device which may be 
attributed to the reduced density of surface trap states of the F-ZnO layer and to the elimination of the electron extraction barrier at its interface with $\mathrm{PC}_{71} \mathrm{BM}$; both significantly decrease the probability of trapassisted recombination and/or electron back scattering and enhance charge transport and thus the measured electron current. Next, transient photovoltage (TPV) measurements were used to probe the charge carrier decay dynamics under an extraction electric field and indicated also that the device with the F-ZnO layer exhibits reduced charge recombination rates and enhanced charge transport characteristics. We carried out TPV measurements under different light intensities resulting in obtaining different $\mathrm{V}_{\mathrm{oc}}$ values in the range between 0.40 and $0.70 \mathrm{~V}$ and we estimated carrier lifetime from the exponential fitting of the TPV curves (Figure $7 \mathrm{~b}$ ). It is obvious that the device with the plasma treated $\mathrm{ZnO}$ layer exhibits longer photogenerated charge carrier lifetimes, which suggest reduced charge recombination rates through passivation of traps. In order to further investigate the effect of $\mathrm{SF}_{6}$ plasma treatment of $\mathrm{ZnO}$ layer on the device built-in potential, we also measured the capacitance-voltage $(\mathrm{C}-\mathrm{V})$ characteristics (in dark) of P3HT:PC ${ }_{71} \mathrm{BM}$ based PSCs for different $\mathrm{ZnO}$ layers. $\mathrm{C}-\mathrm{V}$ measurements in devices based on organic semiconductors usually exhibit MottSchottky characteristics and can be used to evidence the device built-in field ( $\left.\mathrm{V}_{\mathrm{bi}}\right)$, which is also related to the presence of charge extraction barriers at electrode contacts. In Figure 7c the Mott-Schottky characteristics of the devices as derived from the $\mathrm{C}-\mathrm{V}$ measurements by using the formula $\mathrm{C}^{-2}=\left(2 / \mathrm{q} \varepsilon \varepsilon_{0} \mathrm{~N}\right)$ $\left(\mathrm{V}_{\mathrm{bi}}-\mathrm{V}\right)$, where $\varepsilon_{0}$ is the free space permittivity, $\varepsilon$ is the dielectric constant of the blend, $\mathrm{q}$ is the elementary charge and $\mathrm{N}$ is the electron donor concentration, are shown. ${ }^{81}$ The built-in voltage $\left(\mathrm{V}_{\mathrm{bi}}\right)$ is defined by the intersection of the $\mathrm{C}^{-2}$ curve and the horizontal bias axis. For the device with the $\mathrm{ZnO}$ we obtained a $\mathrm{V}_{\mathrm{bi}}$ of $0.45 \mathrm{~V}$ while the use of $\mathrm{F}-\mathrm{ZnO}$ as the cathode interlayer delivered a $\mathrm{V}_{\mathrm{bi}}$ increase of $0.58 \mathrm{~V}$. This increase in $\mathrm{V}_{\mathrm{bi}}$ indicates that the use of the plasma-treated $\mathrm{ZnO}$ interlayer strengthens the device built-in field, mainly due to the lowering of the work function of the cathode, thus mainly contributing to the increase of $\mathrm{V}_{\text {oc. }}$ The effect of fluorine passivation on the photophysical properties of $\mathrm{P} 3 \mathrm{HT}: \mathrm{PC}_{71} \mathrm{BM}$ films on different $\mathrm{ZnO}$ underlayers were also studied. Steady-state photoluminescence measurements (Figure S12) revealed two distinct emission peaks at $1.95 \mathrm{eV}(670 \mathrm{~nm})$ and $1.75 \mathrm{eV}(720 \mathrm{~nm})$ corresponding to the $0-0$ transiton and the 0-1 and 0-2 sidebands. An overall reduction of the PL intensity is observed when the photoactive layer is deposited on the fluorine passivated $\mathrm{ZnO}$ layer, evidencing more efficient dissociation of the photogenerated 
excitons. This is probably due to a decrease of excitons recombination at the interface of P3HT and the metal oxide attributed to the surface passivation effect of fluorine plasma treatment and it is a clear indication of the better electron accepting capability of the plasma treated metal oxide. The latter could be a result of surface defect passivation which lowers the workfunction of $\mathrm{ZnO}$ thus allowing some photogenerated electrons from $\mathrm{P} 3 \mathrm{HT}$ in close proximity to transfer to the $\mathrm{CB}$ of $\mathrm{ZnO}$ and providing another interfacial path for charge separation/transfer. However, a smaller decrease in the higher energy peak intensity is observed versus that of the lower energy peak is observed in the PL spectrum of P3HT deposited on top of the plasma treated metal oxide as shown in Figure 7d, where the normalized PL spectra of the photoactive blend on top of the different metal oxide substrates are presented. This could be the result of the passivation of surface defects of $\mathrm{ZnO}$ via fluorine plasma treatment. These defects are located at about 5.2$5.4 \mathrm{eV}$ below vacuum $(0.8-1.0 \mathrm{eV}$ below the $\mathrm{CB}$ of $\mathrm{ZnO})$ and are therefore nearly aligned with the lower states present in the HOMO of P3HT, if assuming a Gaussian distribution of the HOMO. ${ }^{82,83}$ The recombination of the photogenerated holes coming from the lower HOMO states of P3HT with the electrons trapped in the defect states of $\mathrm{ZnO}$ reduces the high energy decay transitions of P3HT as illustrated in Figure 7e. Passivation of the surface defects of $\mathrm{ZnO}$ reduces the specific hole recombination losses and increases the high energy radiative transitions of the photoabsorber (Figure 7f).

The so far obtained results indicate that our approach of using the fluorine surface passivation of solution processed $\mathrm{ZnO}$ has the ability to significantly improve the characteristics of $\mathrm{P} 3 \mathrm{HT}: \mathrm{PC}_{71} \mathrm{BM}$-based solar cells. Moreover, regardless of the specific donor:acceptor combination system with the fluorine plasma passivation approach of (solution-processed) $\mathrm{ZnO}$ we obtained remarkable efficiency enhancement and superior ambient stability in devices with diverse photoactive layers such as the PCDTBT:PC ${ }_{71} \mathrm{BM}$ and PTB7:PC ${ }_{71} \mathrm{BM}$ systems (Figure 8). It is evident that the trend observed in devices based on P3HT:PC ${ }_{71} \mathrm{BM}$ using different $\mathrm{ZnO}$ layers is also seen for the latter devices with the above systems as the photoactive blend. In particular, in the case of PCDTBT:PC ${ }_{71} \mathrm{BM}$-based PSC the reference device showed a relatively low PCE of $5.0 \%$ and while the device with the $\mathrm{SF}_{6}$ treated $\mathrm{ZnO}$ exhibited significantly improved performance as revealed from the high obtained PCE value of $6.9 \%$ which represents nearly $40 \%$ improvement in comparison with that obtained in the reference device (Figure 8a, Table 1). Similarly, the efficiency of $8.0 \%$ 
obtained in the PTB7:PC ${ }_{71} \mathrm{BM}$-based device with the plasma treated interlayer represent a nearly $45 \%$ improvement over the 5.5\% obtained in the control devices (Figure 8d, Table 1). In all cases the significant PCE enhancement obtained in the devices with the F plasma treated $\mathrm{ZnO}$ layers as compared with the reference ones was primarily attributed to a large increase of the devices photocurrent, followed by an increased in $\mathrm{V}_{\mathrm{oc}}$ and also in the FF. This indicates that the recombination losses of photogenerated carriers are significantly suppressed in the former devices, which support our argument that fluorine incorporation within the $\mathrm{ZnO}$ near surface region causes effective passivation of surface defects and probably surface doping. In addition, the improved EQE measurements (Figures $8 \mathrm{~b}$ and 8e) and the better device stability (Figures $8 \mathrm{c}$ and $8 \mathrm{f}$ ) also verified the beneficial effect of fluorine passivation of $\mathrm{ZnO}$ in the device characteristics. Note that, our results are in full agreement with the passivation and n-type doping effect of $\mathrm{SF}_{6}$ plasma on $\mathrm{TiO}_{2}$ recently demonstrated by $\mathrm{H}$. Seo and co-workers. ${ }^{84}$ These results demonstrate that fluorine passivation of $\mathrm{ZnO}$ films using not only plasma, but potentially also other methods, e.g. the incorporation of fluorine dopant in the precursor solution, may be promising for making high-performing PSCs but also for photonics and various optoelectronic applications.

\section{Conclusion}

The fluorine plasma treatment of $\mathrm{ZnO}$ cathode interlayers was found to be effective in improving both the efficiency and lifetime of polymer solar cells, irrespective of the donor:acceptor combinations used in the photoactive blend. We propose a mechanism according to which a fluorine atom substitutes an oxygen atom or occupies an oxygen vacancy site eliminating a trap state present within the energy gap of $\mathrm{ZnO}$ located near the HOMO level of P3HT, acting as a charge recombination center. Significant surface defect passivation in $\mathrm{ZnO}$ resulted in reduced recombination losses and better overall quality of the cathode contact boosting thus the measured $\mathrm{J}_{\mathrm{sc}}$ and $\mathrm{FF}$ in the devices using the plasma treated interlayers. In addition, the improved $\mathrm{V}_{\mathrm{oc}}$ was attributed to the reduction of the width of the space-charge region after surface defect passivation, which resulted in a downward shift of the band edges having as a net result the reduction of the work function in the $\mathrm{ZnO}$ surface and lowering of the electron extraction barrier at the $\mathrm{ZnO} /$ fullerene interface. Our findings demonstrate that fluorine plasma treatment can be applied for the improvement of the 
surface properties of $\mathrm{ZnO}$ layers, in particular for effective passivation of surface defects, opening a novel and efficient route for the development not only of high performing polymer solar cells but also of related optoelectronic devices such as organic light emitting diodes and perovskite solar cells.

\section{Experimental section}

Preparation of $\mathrm{ZnO}$ films. Solution-processed $\mathrm{ZnO}$ films were prepared following a sol-gel method using zinc acetate in 2-methoxyethanol:2-amino-ethanol as a precursor solution with a concentration of $0.50 \mathrm{M} .^{85}$ The solution was filtered by a $0.45 \mathrm{~m}$ pore size nylon membrane and then spin-coated at $4000 \mathrm{rpm}$. Zinc acetate was purchased from Sigma-Aldrich and used without further purification. The ZnO films were then annealed in air at $100{ }^{\circ} \mathrm{C}$ for about 20 min. The modification of the $\mathrm{ZnO}$ surface was performed using $\mathrm{SF}_{6}$ as a reactive gas; the processes conditions were optimized to a flow rate of 200 standard cubic centimeters per minute (sccm), an input power of $100 \mathrm{Watt}$ chamber pressure of $10 \mathrm{mTorr}$, a substrate temperature $25{ }^{\circ} \mathrm{C}$ and a plasma duration of 5 min. Constant plasma on and off pressure was assured by the means of an automated pressure regulator. For the plasma treatment Alcatel MET DRIE system was utilized. The system comprises an inductively coupled helicon antenna for the plasma generation, mass flow controllers (MFC) for the gas transfer into the processing chamber, a variable position VAT valve, working in the range of background gas pressure up to 100mTorr and a heat/cool transfer mechanism from the substrate holder to the processed sample with a minimum of $-180{ }^{\circ} \mathrm{C}$ up to a maximum of $+45^{\circ} \mathrm{C}$, using $\mathrm{He}$ gas as a heat/cool transfer gas.

Computational part. All theoretical calculations were carried out using the Vienna Ab Initio Simulation Package (VASP). ${ }^{86}$ Plane-wave basis sets and the Perdew-Burke-Ernzerhof (PBE) gradient-corrected exchange-correlation functional was used throughout the computational part. We incorporated an effective Hubbard $\mathrm{U}$ parameter equal to $8.5 \mathrm{eV}$ as implemented and tested by $\mathrm{Li}$ et al. ${ }^{87}$ All calculations were performed via the projector augmented wave (PAW) method, ${ }^{88}$ with a plane-wave cut-off energy of $400 \mathrm{eV}$ and a $\Gamma$ centered k-point grid of $8 \times 8 \times 1$. The tetrahedron method with Blöchl corrections of a width of 0.2 $\mathrm{eV}$ was used to determine how partial occupancies are set for each wave function. The $\mathrm{ZnO}$ surface slab was constructed after $\mathrm{PBE}+\mathrm{U}$ ion optimization, excluding volume, was performed on bulk $\mathrm{ZnO}$ at its 
crystallographic coordinates; these were taken from work done by Kisi et al. ${ }^{89}$ The $\mathrm{ZnO}$ (0002) surface, which according to Siao et al., ${ }^{90}$ is the most stable and exposed crystal surface of $\mathrm{ZnO}$ in the O- and $\mathrm{H}$-rich limits, was modeled using $20 \mathrm{Zn}$ and $24 \mathrm{O}$ atoms within an orthorhombic cell of dimensions $\mathrm{a}=6.50 \AA \mathrm{A}, \mathrm{b}=$ $5.63 \AA$ and $\mathrm{c}=40 \AA$. All surface cells were separated by a vacuum space of $\sim 30 \AA$ along z-axis. Geometry optimization, with maximum atomic forces of $0.01 \mathrm{e} \cdot \AA^{-1}$ was carried out for the top two $\mathrm{ZnO}$ layers emulating surface relaxation, while the bottom three layers were kept fixed at their crystallographic coordinates representing "bulk" $\mathrm{ZnO}$.

Device Fabrication. Polymer solar cells were fabricated on fluorinated tin oxide (FTO) coated glass substrates which were purchased from Sigma-Aldrich and served as the cathode electrode. Substrates were ultrasonically cleaned with a standard solvent regiment (15 min each in acetone, isopropanol and di-ionized water). The $\mathrm{ZnO}$ layer (with a thickness of $40 \mathrm{~nm}$ ) WAS then deposited followed by appropriate annealing and deposition of the photoactive layer. The active layer was consisting of P3HT: $\mathrm{PC}_{71} \mathrm{BM}$ blend $\left(10 \mathrm{mg} \mathrm{ml}^{-1}\right.$ for $\mathrm{P} 3 \mathrm{HT}, 8 \mathrm{mg} \mathrm{ml}^{-1}$ for $\mathrm{PC}_{71} \mathrm{BM}$ in chlorobenzene) with a thickness of $150 \mathrm{~nm}$ or PCDTBT:PC ${ }_{71} \mathrm{BM}(5 \mathrm{mg}$ $\mathrm{ml}^{-1}$ for PCDTBT, $20 \mathrm{mg} \mathrm{ml}^{-1}$ for $\mathrm{PC}_{71} \mathrm{BM}$ in chlorobenzene) with a thickness of $100 \mathrm{~nm}$ or PTB7:PC $71 \mathrm{BM}$ (10 $\mathrm{mg} \mathrm{ml}^{-1}$ for $\mathrm{PTB} 7,15 \mathrm{mg} \mathrm{ml}^{-1}$ for $\mathrm{PC}_{71} \mathrm{BM}$ in chlorobenzene where $3 \%$ per volume of DIO was added) with a thickness of $90 \mathrm{~nm}$. After spin coating, the photoactive layer was annealed either at $130^{\circ} \mathrm{C}$ (P3HT:PC $\left.{ }_{71} \mathrm{BM}\right)$ or at $70{ }^{\circ} \mathrm{C}$ (PCDTBT:PC ${ }_{71} \mathrm{BM}$ and $\left.\mathrm{PTB} 7: \mathrm{PC}_{71} \mathrm{BM}\right)$ for $10 \mathrm{~min}$ in air. Then, an approximately $20 \mathrm{~nm}$-thick under-stoichiometric molybdenum oxide $\left(\mathrm{MoO}_{\mathrm{x}}\right)$ layer was deposited on top of the active layer, using the previously reported solution-processed deposition method, ${ }^{91}$ to serve as the hole extraction layer. The devices were completed with a $200 \mathrm{~nm}$ thick aluminium anode, deposited in a dedicated thermal evaporator at a pressure of $10^{-6}$ Torr through a shadow-mask, which defined the device active area to be equal to $12.56 \mathrm{~mm}^{2}$. The devices were then measured in air at room temperature without additional encapsulation. All chemicals were purchased from Sigma-Aldrich and used with no further purification.

Measurements and Instrumentation. Photoluminescence spectra of $\mathrm{ZnO}$ films were measured using a Horiba Jobin-Yvon iHR320 Spectrometer with a He-Cd laser $(325 \mathrm{~nm})$ as the excitation source. The structural characterization of all samples was carried out by wide angle X-ray diffraction (reflection mode) 
using a Bruker D8 Discover diffractometer with Ni-filtered $\mathrm{Cu}-\mathrm{K} \alpha$ radiation source $(\lambda=1.5406 \AA)$ equipped with a LynxEye position sensitive detector. The steady-state photoluminescence spectra of P3HT on $\mathrm{ZnO}$ substrates were recorded using an Ar+-ion laser operating at $457.9 \mathrm{~nm}$ as excitation source. Surface morphology and structure were investigated with an NT-MDT atomic force microscope (AFM) operated in tapping mode. Absorption measurements were taken using a Perkin Elmer Lampda 40 UV/Vis spectrophotometer. The thicknesses of films were measured with an Ambios XP-2 profilometer and a M2000 Woolam ellipsometer. X-ray photoelectron spectra (XPS) and Ultraviolet Photoelectron Spectra (UPS) were recorded by Leybold EA-11 electron analyzer operating in constant energy mode at pass energy of $100 \mathrm{eV}$ and at a constant retard ratio of $4 \mathrm{eV}$ for XPS and UPS respectively. All binding energies were referred to the $\mathrm{C} 1 \mathrm{~s}$ peak at $284.8 \mathrm{eV}$ of surface adventitious carbon, respectively. The $\mathrm{X}$-ray source for all measurements was an unmonochromatized $\mathrm{Al} \mathrm{K \alpha}$ line at $1486.6 \mathrm{eV}(12 \mathrm{keV}$ with $20 \mathrm{~mA}$ anode current). The valence band spectra of $\mathrm{Zn}$ oxides were evaluated after recording the UPS spectra of about $50 \mathrm{~nm}$ thick films deposited on an FTO substrate. For the UPS measurements, the He I $(21.22 \mathrm{eV})$ excitation line was used. A negative bias of $12.22 \mathrm{~V}$ was applied to the samples during UPS measurements in order to separate secondary electrons originating from sample and spectrometer and to estimate the absolute work function value from the high BE cut-off region of the UPS spectra. The analyzer resolution is determined from the width of the Au Fermi edge to be $0.16 \mathrm{eV}$.

Current density-voltage characteristics of the fabricated solar cells were measured with a Keithley 2400 source-measure unit. Cells were illuminated with a Xe lamp and an AM 1.5G filter to simulate solar light illumination conditions with an intensity of $100 \mathrm{~mW} / \mathrm{cm}^{2}$ (1 sun), as was recorded with a calibrated silicon photodiode. To accurately define the active area of all devices we used aperture masks during the measurements with their area equal to those of the $\mathrm{Al}$ contacts $\left(12.56 \mathrm{~mm}^{2}\right)$. EQE measurements were carried out using an Autolab PGSTAT-30 potentiostat, with a $300 \mathrm{~W}$ Xe lamp in combination with an Oriel 1/8 monochromator for dispersing the light in an area of $0.5 \mathrm{~cm}^{2}$. A Thorlabs silicon photodiode was used for the calibration of the spectra. For the TPV measurements the solar cells were connected to a digital oscilloscope with an input impedance of $1 \mathrm{M} \Omega$. The intensity of the white light was used to control the $\mathrm{V}_{\mathrm{oc}}$ of the devices. A laser with a wavelength of $532 \mathrm{~nm}$ was used as the optical perturbation. The pulse duration 
was set to $1 \mathrm{~ms}$ and the frequency to $100 \mathrm{~Hz}$. The frequency, light intensity and pulse duration were constant, while the photocurrent transient was measured at an impedance of $50 \Omega$. The capacitance-voltage measurements were recorded on devices exhibiting the same architecture as described above (OPVs) at a frequency of $100 \mathrm{KHz}$ and an AC bias of $25 \mathrm{mV}$ by using a Keithley 4200-SCS DC characterization system. The measurements were performed in air at room temperature. All measurements were performed in air.

\section{Acknowledgements}

This work was performed in the framework of "YDISE" project within GSRT's KRIPIS action, funded by Greece and the European Regional Development Fund of the European Union under NSRF 2007-2013 and the Regional Operational Program of Attica. TP acknowledges use of Hartree Centre computational resources via the $3^{\text {rd }}$ BlueJoule Access Programme, under project No. HCBG125, funded by the U.K. Science and Technology Facility Council (STFC), as well as local computational facilities provided by the Faculty of Science and Engineering, University of Chester, U.K.

\section{Supporting Information}

Additional Figures (Figure S1-S12) are included in the Supporting Information: Illustration of defect states in $\mathrm{ZnO}, \mathrm{UV}$-vis absorption and transmission spectra of different $\mathrm{ZnO}$ layers, XPS wide scans and S 2p peaks of $\mathrm{SF}_{6}$ treated $\mathrm{ZnO}$ layer, additional theoretical calculations, $\mathrm{UV}$-vis absorption, $\mathrm{XRD}$ patterns and AFM topographies of $\mathrm{P} 3 \mathrm{HT}: \mathrm{PC}_{71} \mathrm{BM}$ films on different $\mathrm{ZnO}$ layers, contact angle measurements of deionized water and $\mathrm{P} 3 \mathrm{HT}: \mathrm{PC}_{71} \mathrm{BM}$ drops on different $\mathrm{ZnO}$ surfaces and steady-state photoluminescence spectra of P3HT:PC ${ }_{71} \mathrm{BM}$ films on different $\mathrm{ZnO}$ samples. 


\section{References}

1. G. Li, V. Shrotriya, J. Huang, Y. Yao, T. Moriarty, K. Emery, Y. Yang, Nat. Mater, 2005, 4, 864.

2. F. He, L. Yu, J. Phys. Chem. Lett., 2011, 2, 3102.

3. Y. J. Cheng, S. H. Yang, C. S. Hsu, Chem. Rev, 2009, 109, 5868.

4. S. K. Hau, H.-L. Yip, A. K. Y. Jen, Polym. Rev., 2010, 50, 474.

5. R. Po, C. Carbonera, A. Bernardi, N. Camaioni, Energy Environ. Sci., 2011, 4, 285.

6. G. Li, R. Zhu, Y. Yang, Nat. Photon., 2012, 6, 153.

7. S. Zhang, L. Ye, W. Zhao, D. Liu, H. Yao, J. Hou, Macromolecules, 2014, 47, 4653.

8. L. Ye, S. Zhang, W. Zhao, H. Yao. J. Hou, Chem. Mater., 2014, 26, 3603.

9. T. L. Nguyen, H. Choi, S. J. Ko, M. A. Uddin, B. Walker, S. Yum, J. E. Jeong, M. H. Yun, T. J. Shin, S. Hwang, J. Y. Kim, H. Y. Woo, Energy Environ. Sci., 2014, 7, 3040.

10. J. You, L. Dou, K. Yoshimura, T. Kato, K. Ohya, T. Moriarty, K. Emery, C.-C. Chen, J. Gao, G. Li and Y. Yang, Nat. Commun., 2013, 4, 1.

11. A. R. b. M. Yussof, D. Kim, H. P. Kim, F.K. Shneider, W. J. da Silva, J. Jang, Energy Environ. Sci., 2015, 8, 303.

12. X. Che, X. Xiao, J. D. Zimmermann, D. Fan, S. R. Forrest, Adv. Energy Mater., 2014, 4, 1400568.

13. C.-C. Chen, W.-H. Chang, K. Yoshimura, K. Ohya, J, You, J. Gao, Z. Hong, Y. Yang, Adv. Mater., 2014, 26, 5670.

14. Z. Liang, Q. Zhang, L. Jiang, G. Cao, Energy Environ. Sci., 2015, 8, 3442.

15. C.-C. Chueh, C.-Z. Li, A. K.-Y. Jen, Energy Environ. Sci., 2015,8, 1160.

16. R. Po, C. Carbonera, A. Bernardi, N. Camaioni, Energy Environ. Sci., 2011, 4, 285.

17. Y. Sun, J. H. Seo, C. J. Takacs, J. Seifter, A. J. Heeger, Adv. Mater., 2011, 23, 1679.

18. M. S. White, D. C. Olson, S. E. Shaheen, N. Kopidakis, D. S. Ginley, Appl. Phys. Lett., 2006, 89, 143517.

19. S. K. Hau, H.-L. Yip, N. S. Baek, J. Zou, K. O'Malley, A. K. Y. Jen, Appl. Phys. Lett., 2008, 92 , 253301. 
20. H.-L. Yip, A. K. Y. Jen, Energy Environ. Sci., 2012, 5, 5994.

21. M. Jorgensen, K. Norrman, S. A. Gevorgyan, T. Tromholt, B. Andreasen, F. C. Krebs, Adv. Mater., 2012, 24, 580.

22. A. K. K. Kyaw, X. W. Sun, C. Y. Jiang, G. Q. Lo, D. W. Zhao, D. L. Kwong, Appl. Phys. Lett., 2008, 93, 221107.

23. Y. W. Heo, D. P. Norton, L. C. Tien, Y. Kwon, B. S. Kang, F. Ren, S. J. Pearton, J. R. LaRoche, Mater. Sci. Eng., 2004, 47, 1.

24. K. Ellmer, J. Phys. D: Appl. Phys., 2001, 34, 3097.

25. M. Vasilopoulou, E. Polydorou, A. M. Douvas, L. C. Palilis, S. Kennou, P. Argitis, Energy Environ. Sci., 2015, 8, 2448.

26. A. Gadisa, Y. Liu, E. T. Samulski, R. Lopez, Appl. Phys. Lett., 2012, 100, 253903.

27. M. Hartel, S. Chen, B. Swerdlow, H.-Y. Hsu, J. Manders, K. Schanze, F. So, ACS Appl. Mater. Interfaces, 2013, 5, 7215.

28. S. Bai, Y. Jin, X. Liang, Z. Ye, Z. Wu, B. Sun, Z. Ma, Z. Tang, J. Wang, U. Würfel, F. Gao, F. Zhang, Adv. Energy Mater., 2015, 5, 1401606.

29. A. F. Kohan, G. Ceder, D. Morgan, C. G. Van de Walle, Phys. Rev. B, 2000, 61, 15019.

30. A. Janotti, C. G. Van de Walle, Appl. Phys. Lett., 2005, 87, 122102.

31. A. Janotti, C. G. Van de Walle, Phys. Rev. B, 2007, 76, 165202.

32. M. R. Lilliedal, A. J. Medford, M. V. Madsen, K. Norrman, F. C. Krebs, Sol. Energy Mater. Sol. Cells, 2010, 94, 2018.

33. A. J. Morfa, B. I. MacDonald, J. Subbiah, J. J. Jasieniak, Sol. Energy Mater. Sol. Cells, 2014, 124, 211.

34. S. Wilken, J. Parisi, H. Borchert, J. Phys. Chem. C, 2014, 118, 19672.

35. Q. Bao, X. Liu, Y. Xia, F. Gao, L.-D. Kauffmann, O. Margeat, J. Ackermann, M. Fahlman, J. Mater. Chem. A, 2014, 2, 17676.

36. Z. Yin, J. Wei Q. Zheng, Adv. Sci., 2016, 1500362, doi: 10.1002/advs.201500362. 
37. J. M. Cho, S. W. Kwak, H. Aqoma, J. W. Kim, W. S. Shin, S.-J. Moon, S.-Y. Jang, J. Jo, Org. Electron., 2014, 15, 1942.

38. T. Hu, F. Li, K. Yuan, Y. Chen, ACS Appl. Mater. Interfaces, 2013, 5, 5763.

39. S. Shao, K. Zheng, T. Pullerits, F. Zhang, ACS Appl. Mater. Interfaces, 2013, 5, 380.

40. H.-L. Yip, S. K. Hau, N. S. Baek, H. Ma, A. K.-Y. Jen, Adv. Mater., 2008, 20, 2376.

41. Y. E. Ha, M. Y. Jo, J. Park, Y.-C. Kang, S. I. Yoo, J. H. Kim, J. Phys. Chem. C, 2013, 117, 2646.

42. Y. E. Ha, M. Y. Jo, J. Park, Y.-C. Kang, S.-J. Moon, J. H. Kim, Synth. Met., 2014, 187, 113.

43. I. Lange, S. Reiter, J. Kniepert, F. Piersimoni, M. Pätzel, J. Hildebrandt, T. Brenner, S. Hecht, D. Neher, Appl. Phys. Lett., 2015, 106, 113302.

44. P. Li, X. Li, C. Sun, g. Wang, J. Li, T. Jiu, J. Fang, Sol. Energy Mater. Sol. Cells, 2014, 126, 36.

45. S. K. Hau, H.-L. Yip, O. Acton, N. S. Baek, H. Ma, A. K.-Y. Jen, J. Mater. Chem., 2008, 18, 5113.

46. C.-H. Hsieh, Y.-J. Cheng, P.-J. Li, C.-H. Chen, M. Dubosc, R.-M. Liang, C.-S. Hsu, J. Am. Chem. Soc., 2010, 132, 4887.

47. S. Bai, Y. Jin, X. Liang, Z. Ye, Z. Wu, B. Sun, Z. Ma, Z. Tang, J. Wang, U. Würfel, F. Gao, F. Zhang, Adv. Energy Mater., 2014, 5, 1401606.

48. H. Oh, J. Krantz, I. Litzov, T. Stubhan, L. Pinna, C. J. Brabec, Sol. Energy Mater. Sol. Cells, $2011,95,2194$.

49. K.-S. Shin, K.-H. Lee, H. H. Lee, D. Choi, S.-W. Kim, J. Phys. Chem. C, 2010, 114, 15782.

50. J. Alstrup, M. Jørgensen, A. J. Medford, F. C. Krebs, ACS Appl. Mater. Interfaces, 2010, $2,2819$.

51. R. Søndergaard M. Helgesen, M. Jørgensen, F. C. Krebs, Adv. Energy Mater., 2011, 1, 68.

52. S. Trost, K. Zilberberg, A. Behrendt, A. Polywka, P. Görrn, P. Reckers, J. Maibach, T. Mayer, T. Riedl, Adv. Energy Mater., 2013, 3, 1437.

53. K. P. Musselman, S. Albert-Seifried, R. L. Z. Hoye, A. Sadhanala , D. Muñoz-Rojas , J. L. MacManus-Driscoll, R. H. Friend, Adv. Funct. Mater., 2014, 24, 3562.

54. V. Papamakarios, E. Polydorou, A. Soultati, N. Droseros, D. Tsikritzis, A. M. Douvas, L. Palilis, M. Fakis, S. Kennou, P. Argitis, M. Vasilopoulou, ACS Appl. Mater. Interfaces, 2016, 8, 1194. 
55. H. L. Gao, X. W. Zhang, J. H. Meng, Z. G. Yin, L. Q. Zhang, J. L. Wu, X. Liu, J. Mater. Chem. A, 2015, 3, 3719 .

56. H. S. Yoon, K. S. Lee, T. S. Lee, B. Cheong, D. K. Choi, D. H. Kim, W. M. Kim, Sol. Energy Mater. Sol. Cells, 2008, 92, 1366.

57. B. Liu, M. Gu, X. Liu, S. Huang, C. Ni, Appl. Phys. Lett., 2010, 97, 122101.

58. S. Prucnal, . Gao, S. Zhou, J. Wu, H. Cai, O. D. Gordan, D. R. T. Zahn, G. Larkin, M. Helm. W. Skorupa, Appl. Phys. Lett., 2014, 105, 221903.

59. J.-S. Seo, J.-H. Jeon, Y. H. Hwang, H. Park, M. Ryu, S.-H. Ko Park, B.-S. Bae, Sci. Rep., 2013, 3, 2085.

60. J.-H. Jeon, Y. H. Hwang, B.-S. Bae, Electrochem. Solid State Lett., 2012, 15, H123.

61. S. Cho, J. Ma, Y. Kim, Y. Sun, G. K. L. Wong, J. B. Ketterson, Appl. Phys. Lett., 1999, 75, 276.

62. P. H. Kasai, Phys. Rev., 1963, 130, 989.

63. F. A. Kröger, H. J. Vink, J. Chem. Phys., 1954, 22250.

64. A. Janotti, C. G. Van de Walle, Appl. Phys. Lett., 2005, 87, 122102.

65. K. H. Tam, C. K. Cheung, Y. H. Leung, A. B. Djurišić, C. C. Ling, C. D. Beling, S. Fung, W. M. Kwok, W. K. Chan, D. L. Phillips, L. Ding, W. K. Ge, J. Phys. Chem. B, 2006, 110, 20865.

66. V. Gavryushin, G. Raciukaitis, D. Juodzbalis, A. Kazlauskas, V. Kubertavicius, J. Cryst. Growth, 1994, 138, 924.

67. C. Cheng, H. He, Y. Lu, K. Wu, Z. Ye, ACS Appl. Mater. Interfaces, 2013, 5, 6354.

68. S.-H. Ko Park, Y. E. Lee, J. Mater. Sci., 2004, 39, 2195.

69. H. Y. Xu, Y. C. Liu, J. G. Ma, Y. M. Luo, Y. M. Lu, D. Z. Shen, J. Y. Zhang, X. W. Fan, R. Mu, J. Phys. Condens. Matter, 2004, 16, 5143.

70. N. K. Shrestha, R. Hahn, K. Lee, A. Tighineanu, P. Schmuki, ECS Electrochem. Lett., 2013, 3, E1.

71. Y. Kawamotoa, K. Ogurab, M. Shojiyab, M. Takahashib, K. Kadono, J. Fluorine Chem., 1999, 96, 135.

72. B. Liu, M. Gu, X. Liu, S. Huang, C. Ni, Appl. Phys. Lett., 2010, 97, 122101. 
73. S. Jeong, Y.-G. Ha, J. Moon, A. Facchetti, T. J. Marks, Adv. Mater., 2010, 22, 1346.

74. L.-H. Lee, Y.-J. Chang, G. S. Herman, C. -H. Chang, Adv. Mater., 2007, 19, 843.

75. Ü. Özgür, Y. I. Alivov, C. Liu, A. Teke, M. A. Reshchikov, S. Doğan, V. S. Avrutin, J. Cho, H. A. Morko, J. Appl. Phys., 2005, 98, 041301: 1-103, doi: 10.1063/1.1992666.

76. A. Sharma, J. B. Franklin, B. Singh, G. G. Andersson, D. A. Lewis, Org. Electron., 2015, 24, 131.

77. W. Pong, K. Okada, Phys. Rev. B, 1979, 19, 5307.

78. R. Poole, Phys. Rev. B, 1979, 20, 1733.

79. R. J. Collins, D. G. Thomas, Phys. Rev., 1958, 112, 388.

80. A. Janotti, C. G. Van de Walle, Rep. Prog. Phys., 2009, 72, 126501.

81. J. A. Carr1, S. Chaudhary, Appl. Phys. Lett., 2012, 100, 213902.

82. P. Pingel, D. Neher, Phys. Rev. B, 2013, 87, 115209.

83. Y. Zhang, B. de Boer, P. W. M. Blom, Adv. Funct. Mater., 2009, 19, 1901.

84. H. Seo, L. R. Baker, A. Hervier, J. Kim, J. L. Whitten, G. A. Somorjai, Nanoletters, 2011, 11, 751.

85. E. Polydorou, E. Makarona, A. Soultati, D. G. Georgiadou, T. Kyrasta, T. Speliotis, C. Tsamis, N. Papanikolaou, P. Argitis, I. Kostis, A. Kokkosis, D. Davazoglou, M. Vasilopoulou, Microelectron. Eng., 2014, 19, 100.

86. J. P. Perdew, K. Burke, M. Ernzerhof, Phys. Rev. Lett., 1996, 77, 3865.

87. H. Li, L. K. Schirrar, J. Shim, H. Cheun, B. Kippelen, O. L. A. Monti, L.-L. Bredas, Chem. Mater., 2012, 24, 3044.

88. P. E. Blöchl, Physical Review B, 1994. 50, 17953.

89. E. H. Kisi, M. M. Elcombe, Acta Crystallogr., Sect. C: Struct. Commun., 1989, 45, 1867.

90. Siao, Y.-J., P.-L. Liu, and Y.-T. Wu, Applied Physics Express, 2011, 4, 125601.

91. A.Soultati, A. M. Douvas, D. G. Georgiadou, L. C. Palilis, T. Bein, J. M. Feckl, S. Gardelis, M. Fakis, S. Kennou, P. Falaras, T. Stergiopoulos, N. A. Stathopoulos, D. Davazoglou, P. Argitis, M. Vasilopoulou, Adv. Energy Mater., 2014, 4, 1300896. 


\section{Figures captions}

Figure 1 (a) Steady-state photoluminescence spectra of solution processed $\mathrm{ZnO}$ films (40 nm thick) before and after surface treatment with $\mathrm{SF}_{6}$ plasma for 5 min. (b) X-ray diffraction patterns obtained in the same films. (c) The crystal structure of $\mathrm{ZnO}$. 2-Dimentional atomic force microscopy (AFM) topographies $(5 \times 5 \mu \mathrm{m})$ of solution processed $\mathrm{ZnO}$ films (d) before and (e) after surface treatment with $\mathrm{SF}_{6}$ plasma.

Figure 2 (a) $\mathrm{Zn} 2 \mathrm{p}_{3 / 2}$ core level peaks of the XPS spectra of $40 \mathrm{~nm}$ thick solution processed $\mathrm{ZnO}$ before and after surface treatment with $\mathrm{SF}_{6}$ plasma. (b) $\mathrm{F}$ 1s peak of the XPS spectrum of $\mathrm{SF}_{6}$ treated $\mathrm{ZnO}$ surface. (c) and (d) $\mathrm{O}$ 1s core level peaks of the XPS spectra of $\mathrm{ZnO}$ before and after surface treatment with $\mathrm{SF}_{6}$ plasma, respectively.

Figure 3 (a) The density of states (DOS) of the O-terminated $\mathrm{ZnO}(0002)$ surface; the total DOS is plotted in solid black line, along with the partial DOS for zinc atoms, in black dashed line, and oxygen atoms, in red solid line $\left(\mathrm{E}_{\mathrm{F}}=0 \mathrm{eV}\right)$. (b) The DOS of the $\mathrm{ZnO}(0002)$ surface after $25 \%$ of surface $\mathrm{O}$ atoms are substituted by $\mathrm{F}$ atoms. (c) The DOS of the $\mathrm{ZnO}(0002)$ surface when it is fully fluorinated with one $\mathrm{H}$ atom for every two $\mathrm{F}$ atoms adsorbed on the surface forming bonds with nearest $\mathrm{F}$ atoms. (d) Proposed passivation effect of fluorine atom in zinc oxide atomic structure: fluorine atoms coming from the dissociation of $\mathrm{SF}_{6}$ molecules substitute the oxygen lattices while also may occupy the oxygen vacancies reducing the electron trap sites in both cases. They may also form hydrogen bond with hydroxyl groups present on ambient air.

Figure 4 (a) UPS spectra taken on the solution processed $\mathrm{ZnO}$ films deposited on an FTO substrate before and after passivation with fluorine-containing plasma. (b) Schematic representation of the proposed energy band diagram of the surface of the $\mathrm{ZnO}$ films before and after passivation with $\mathrm{SF}_{6}$ plasma.

Figure 5 (a) The inverted device architecture and the chemical structures of the organic semiconductors

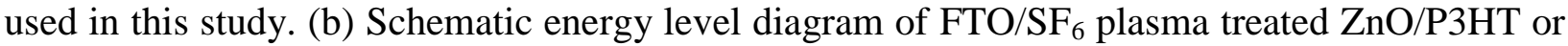
PCDTBT or PTB7:PC ${ }_{71} \mathrm{BM} / \mathrm{MoO}_{x} / \mathrm{Al}$ interfaces present in the devices under study. 
Figure 6 Current density versus voltage (J-V) characteristics (a) under 1.5 AM illumination and (b) in dark, respectively, of the $\mathrm{P} 3 \mathrm{HT}: \mathrm{PC}_{71} \mathrm{BM}$ based devices fabricated on glass/FTO substrates and using $\mathrm{ZnO} / \mathrm{SF}_{6}$ :-sZnO as cathode interlayers. (c) EQE measurements of the same devices. (d), (e) and (f) Variation over time of short-circuit current, open-circuit voltage and fill factor, respectively, for the $\mathrm{P} 3 \mathrm{HT}: \mathrm{PC}_{71} \mathrm{BM}$-based devices using different $\mathrm{ZnO}$ cathode interlayers.

Figure 7 (a) J-V curves in semi-logarithmic scale obtained in electron-only P3HT:PC 71 BM-based devices with the different $\mathrm{ZnO}$ cathode interfaces, measured in the dark. (b) Charge carrier lifetime vs $\mathrm{V}_{\text {oc }}$ of the same devices. (c) Mott-schottky plots derived from capacitance-voltage measurements of the same devices. (d) Steady-state photoluminescence spectra of P3HT:PC 71 BM films deposited on $\mathrm{ZnO}$ layers w/o and with $\mathrm{SF}_{6}$ plasma surface treatment. Illustration of the allowed transitions in $\mathrm{P} 3 \mathrm{HT}$ deposited on (e) $\mathrm{ZnO}$ and (f) $\mathrm{SF}_{6}$ plasma treated $\mathrm{ZnO}$.

Figure 8 (a), (d) Current density versus voltage (J-V) characteristics under 1.5 AM illumination of PSCs based on PCDTBT:PC ${ }_{71} \mathrm{BM}$ and $\mathrm{PTB} 7: \mathrm{PC}_{71} \mathrm{BM}$ using different solution-processed $\mathrm{ZnO}$ interlayers. (b), (e) EQE measurements of the same devices. (c), (f) Variation of PCE versus time of the same devices. 
Table 1 Device characteristics of polymer solar cells having the configuration Glass /FTO/solution-processed ZnO before and after $\mathrm{SF}_{6}$ plasma surface treatment/active layer $/ \mathrm{MoO}_{\mathrm{x}} / \mathrm{Al}$ (mean values and standard deviations were extracted from a batch of 27 devices).

\begin{tabular}{|c|c|c|c|c|c|c|}
\hline & $\begin{array}{c}\mathbf{J}_{\mathbf{s c}} \\
\left(\mathbf{m A} / \mathbf{c m}^{2}\right)\end{array}$ & $\begin{array}{l}\mathbf{V}_{\text {oc }} \\
(\mathbf{V})\end{array}$ & FF & $\begin{array}{r}\text { PCE } \\
(\%)\end{array}$ & $\begin{array}{c}R_{\mathrm{s}} \\
\left(\Omega \mathrm{cm}^{2}\right)\end{array}$ & $\begin{array}{c}\mathbf{R}_{\text {sh }} \\
\left(\Omega \mathbf{c m}^{2}\right)\end{array}$ \\
\hline & \multicolumn{6}{|l|}{ P3HT:PC ${ }_{71} B M$} \\
\hline $\mathrm{ZnO}$ & $8.2( \pm 0.27)$ & $0.60( \pm 0.02)$ & $0.59( \pm 0.01)$ & $2.9( \pm 0.22)$ & 5.3 & 1150 \\
\hline F-ZnO & $10.8( \pm 0.22)$ & $0.63( \pm 0.01)$ & $0.67( \pm 0.01)$ & $4.6( \pm 0.18)$ & 2.1 & 1600 \\
\hline \multicolumn{7}{|c|}{ PCDTBT:PC ${ }_{71} B M$} \\
\hline $\mathrm{ZnO}$ & $8.80( \pm 0.30)$ & $0.82( \pm 0.20)$ & $0.70( \pm 0.10)$ & $5.0( \pm 0.35)$ & 6.2 & 650 \\
\hline F-ZnO & $11.2( \pm 0.20)$ & $0.85( \pm 0.20)$ & $0.73( \pm 0.10)$ & $6.9( \pm 0.20)$ & 2.4 & 1300 \\
\hline \multicolumn{7}{|c|}{ PTB7:PC ${ }_{71} B M$} \\
\hline $\mathrm{ZnO}$ & $10.7( \pm 0.25)$ & $0.77( \pm 0.02)$ & $0.67( \pm 0.01)$ & $5.5( \pm 0.20)$ & 8.1 & 700 \\
\hline F-ZnO & $14.4( \pm 0.25)$ & $0.80( \pm 0.02)$ & $0.70( \pm 0.01)$ & $8.0( \pm 0.20)$ & 2.9 & 1050 \\
\hline
\end{tabular}


Figures

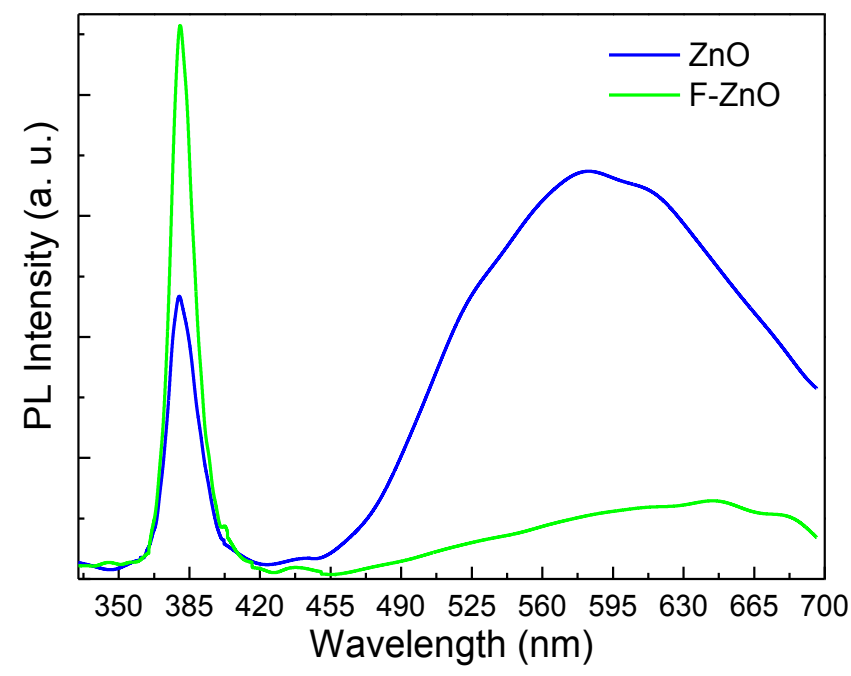

(a)

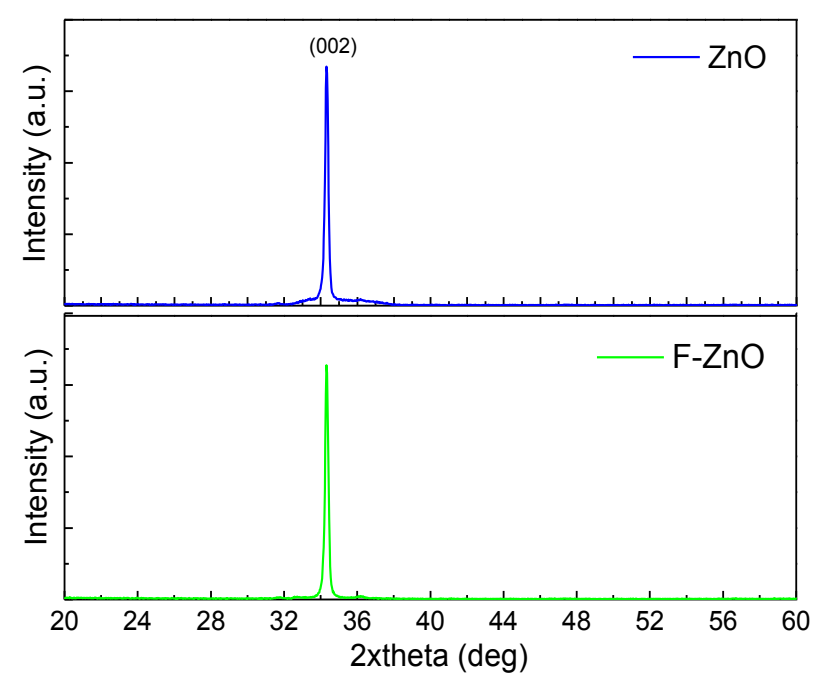

(b)

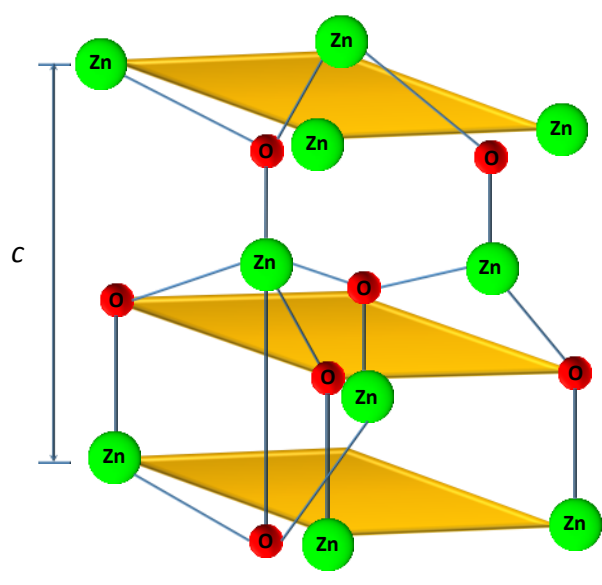

(c)

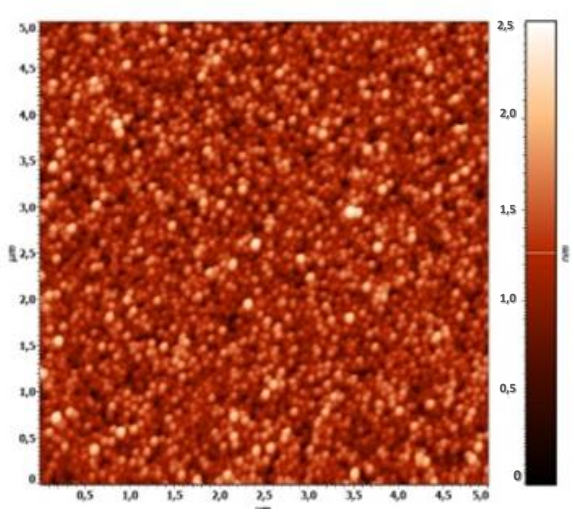

(d)

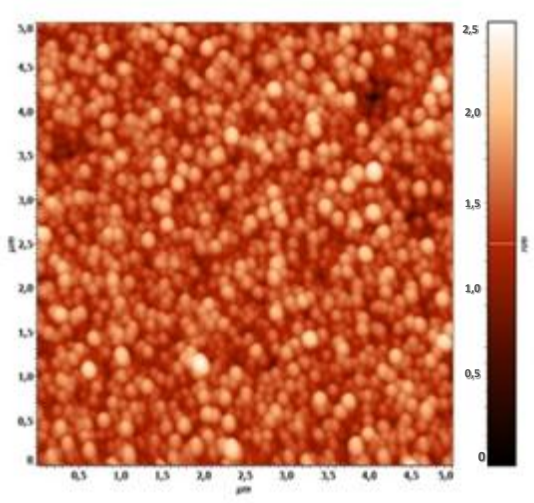

(e)

Figure 1 


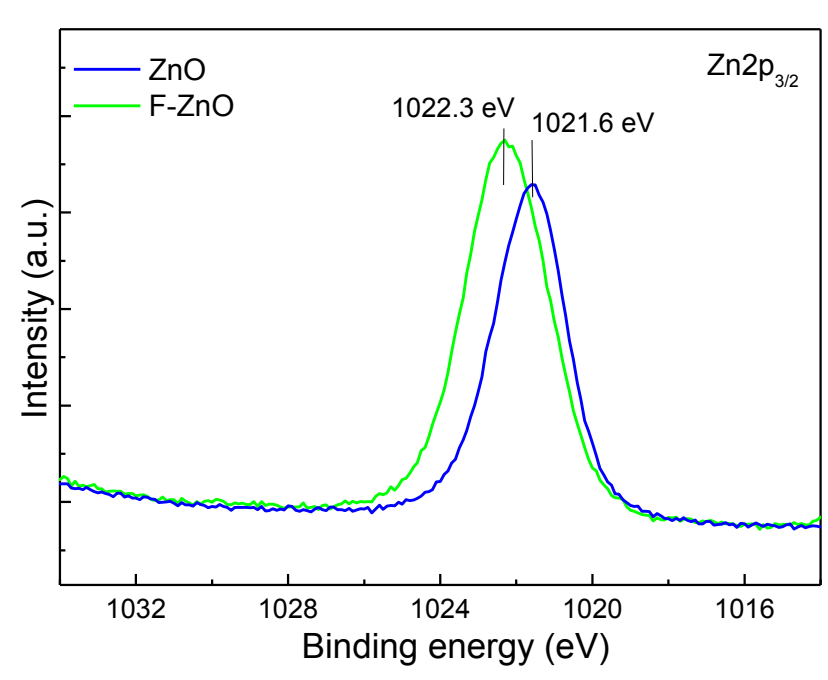

(a)

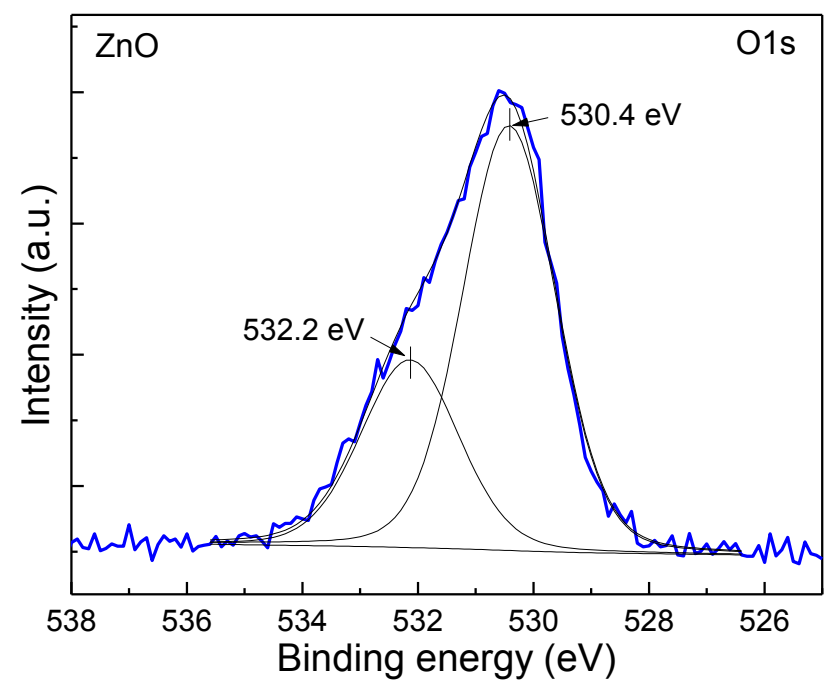

(c)

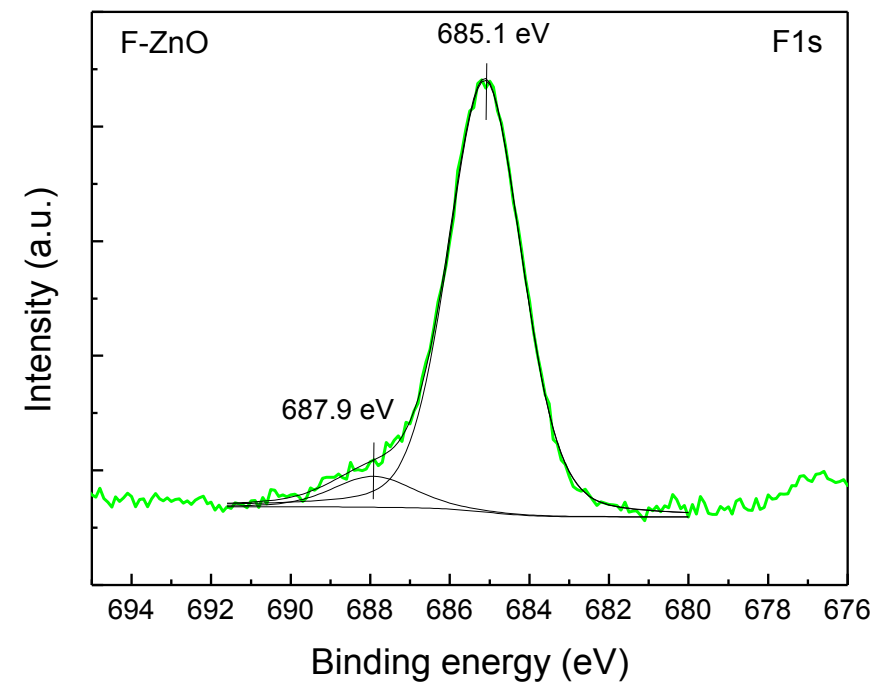

(b)

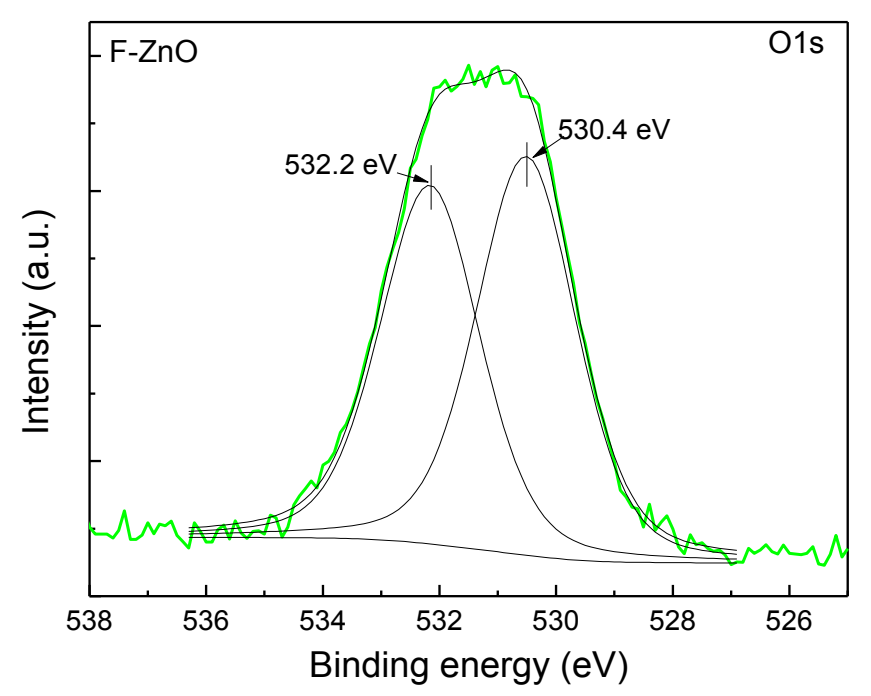

(d)

Figure 2 


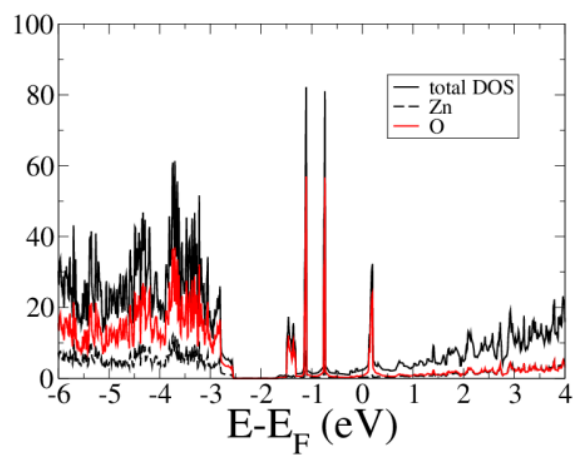

(a)

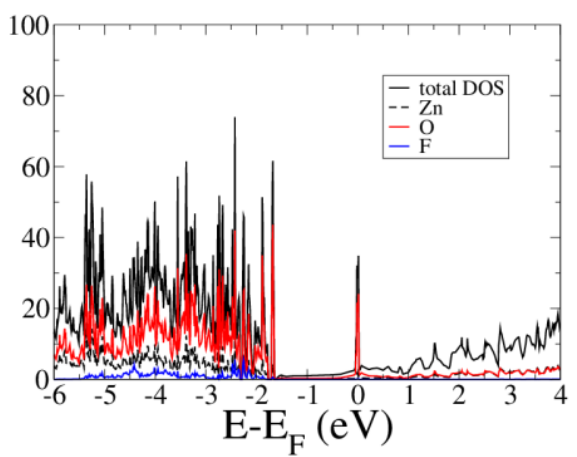

(b)

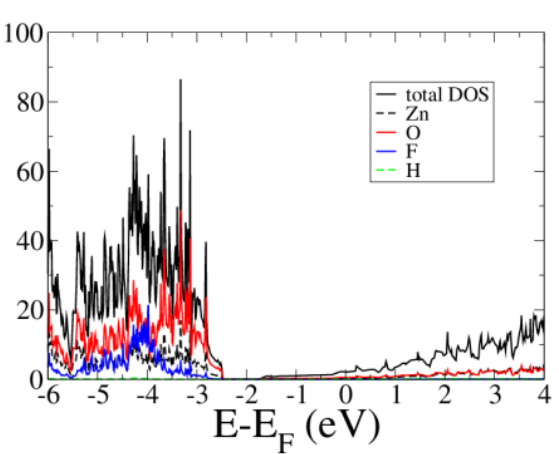

(c)

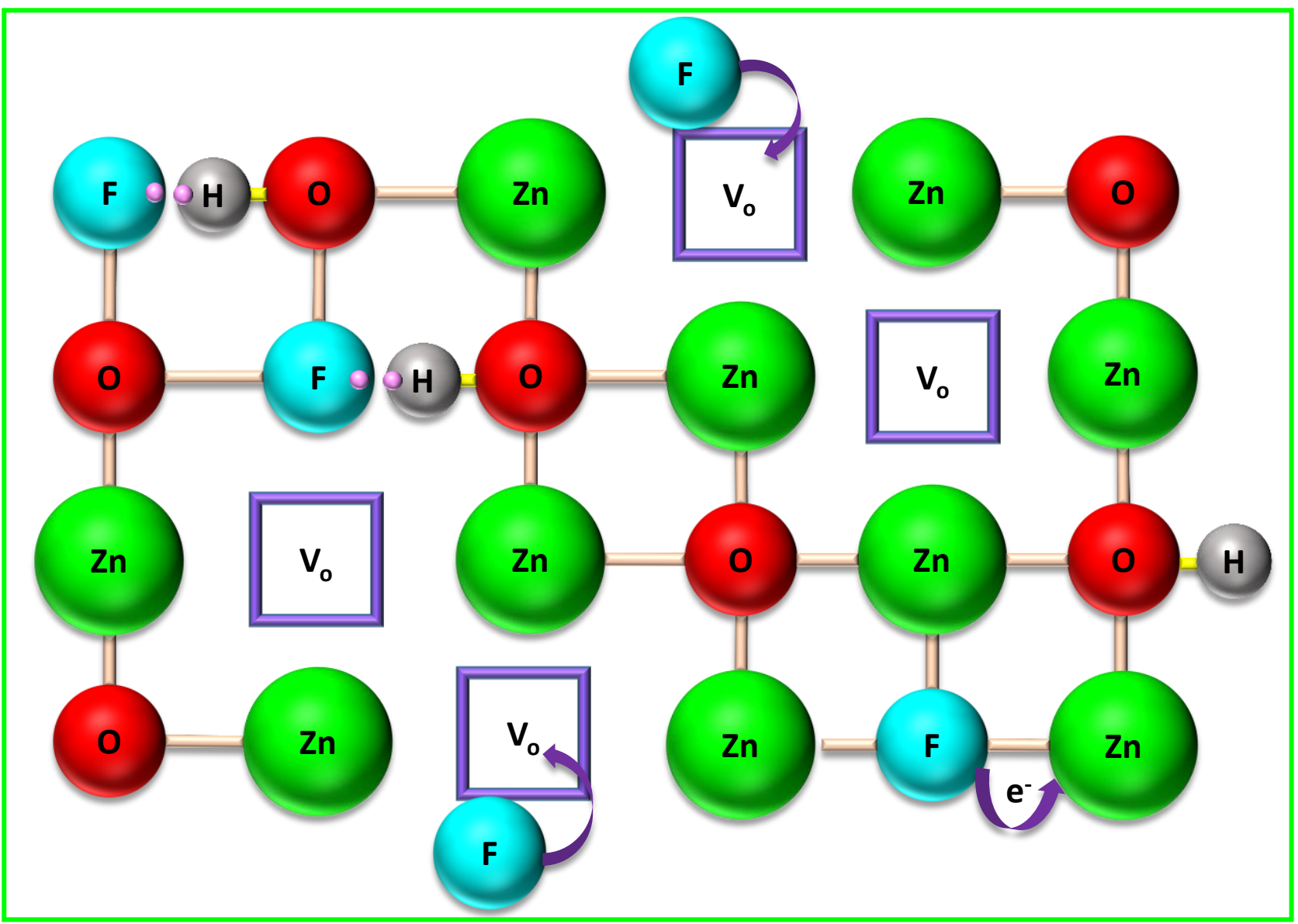

(d)

Figure 3 


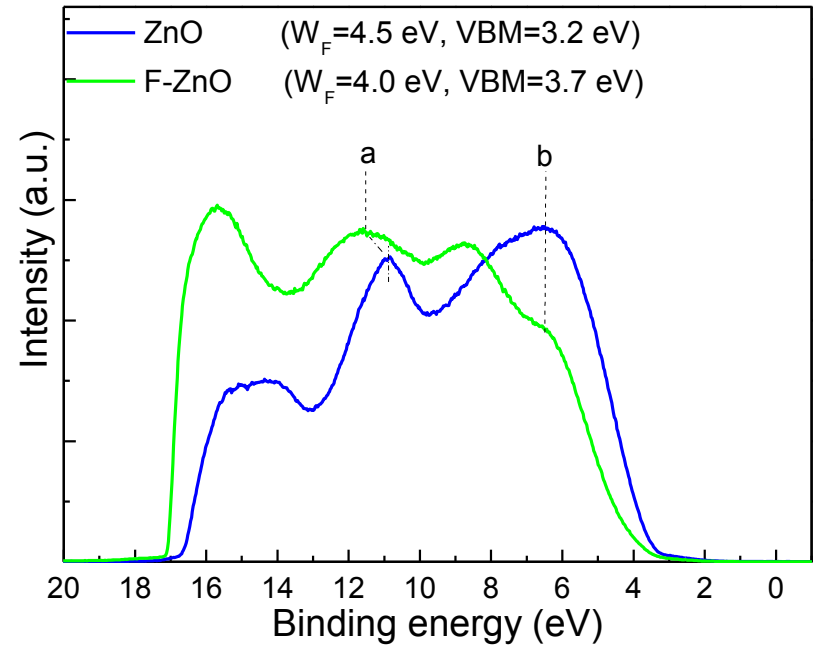

(a)

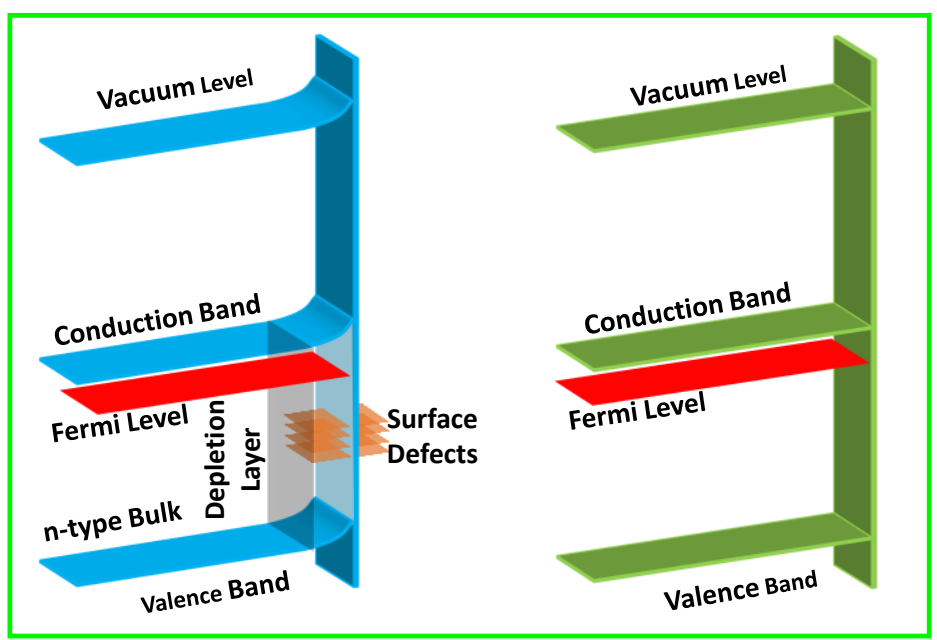

(b)

Figure 4 


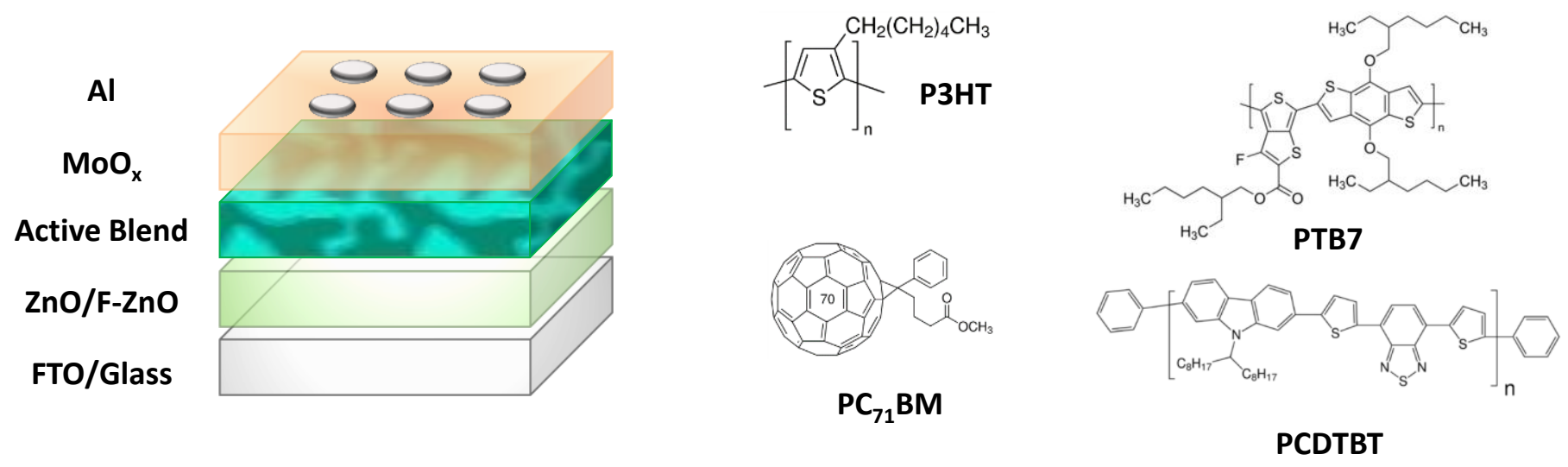

(a)

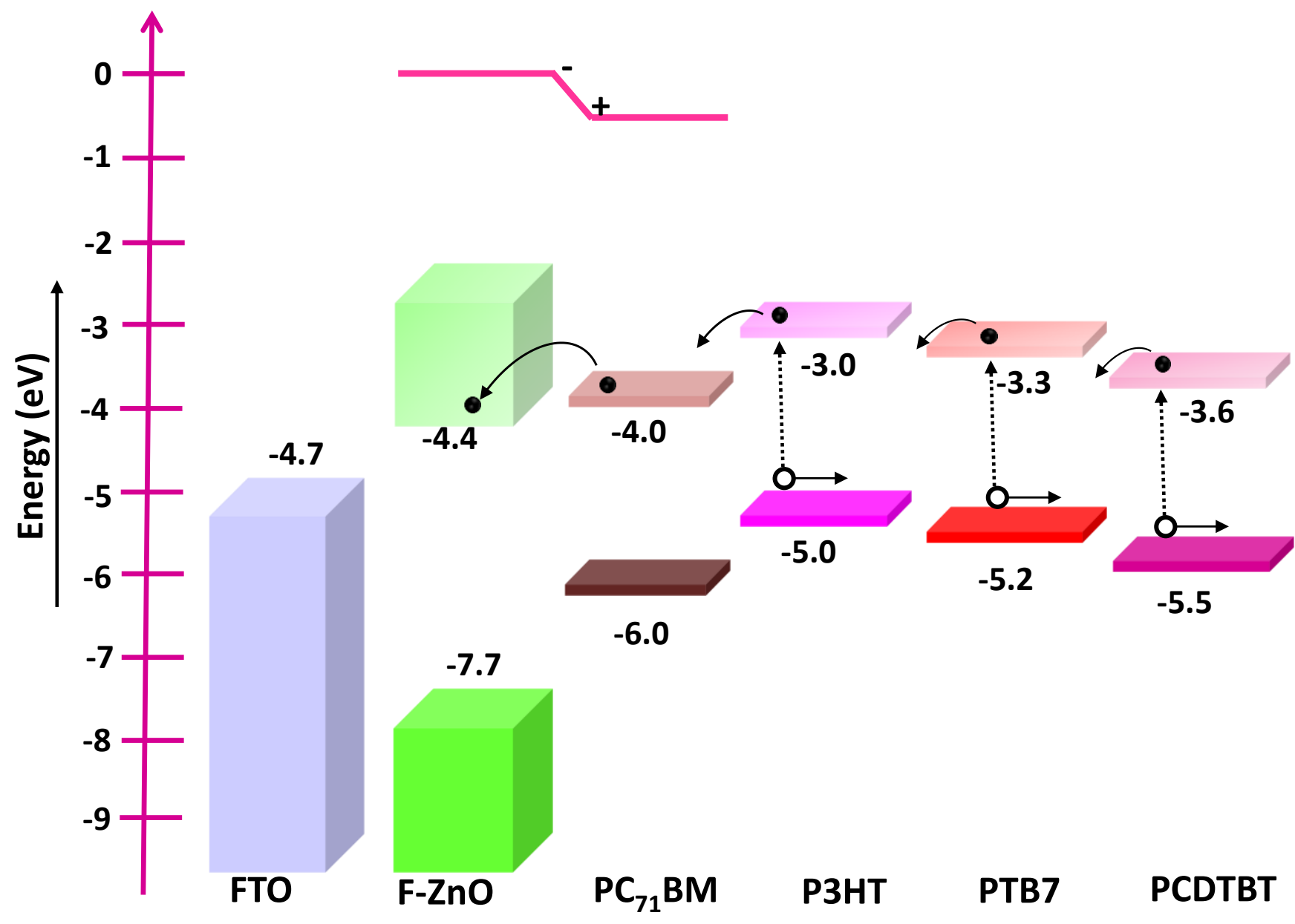

(b)

Figure 5 


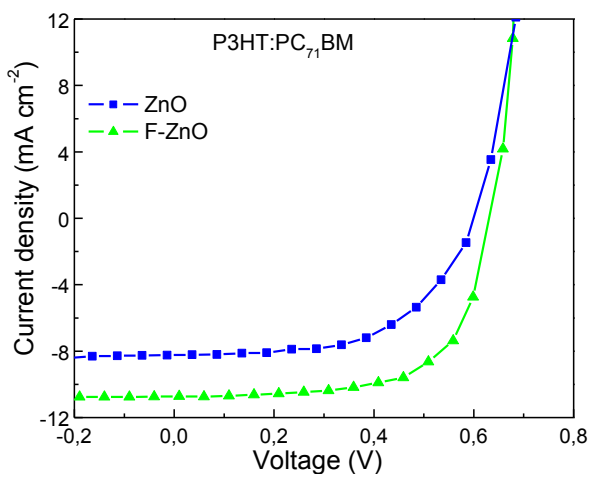

(a)

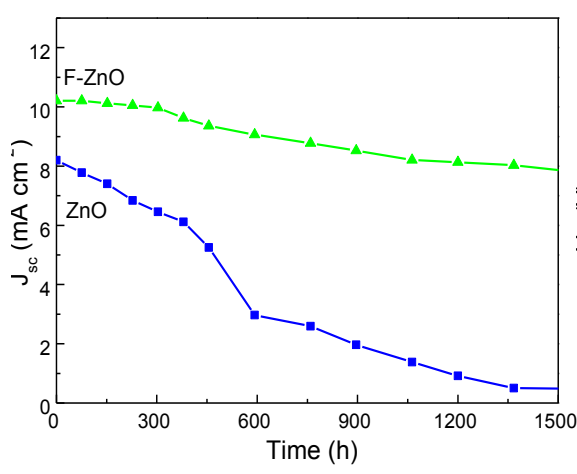

(d)

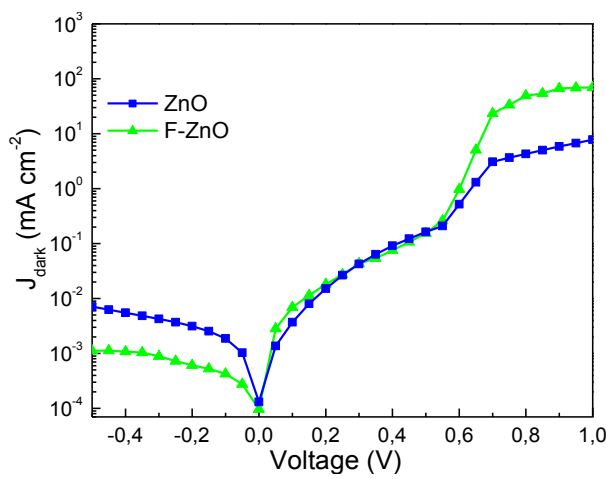

(b)

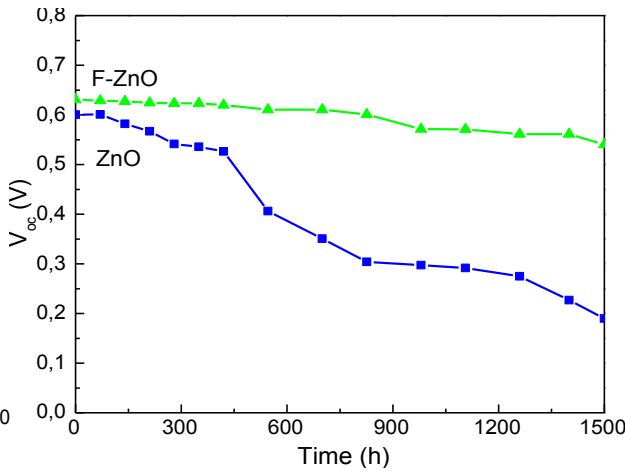

(e)

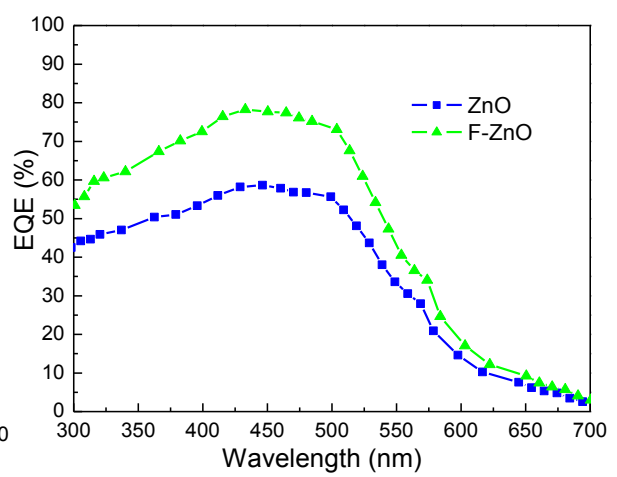

(c)

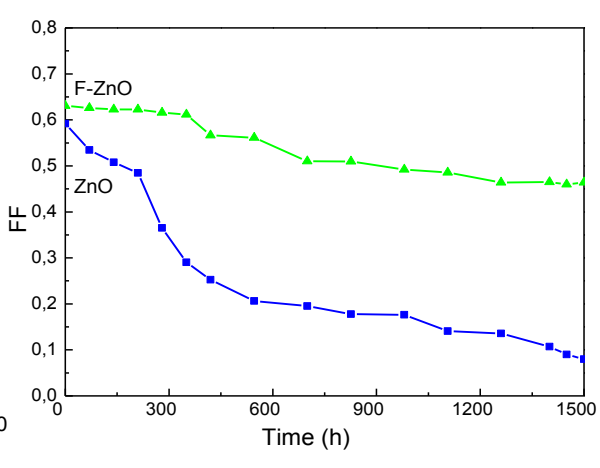

(f)

Figure 6 


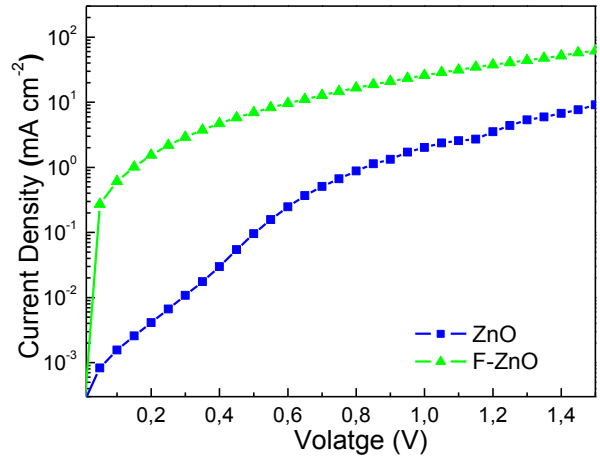

(a)

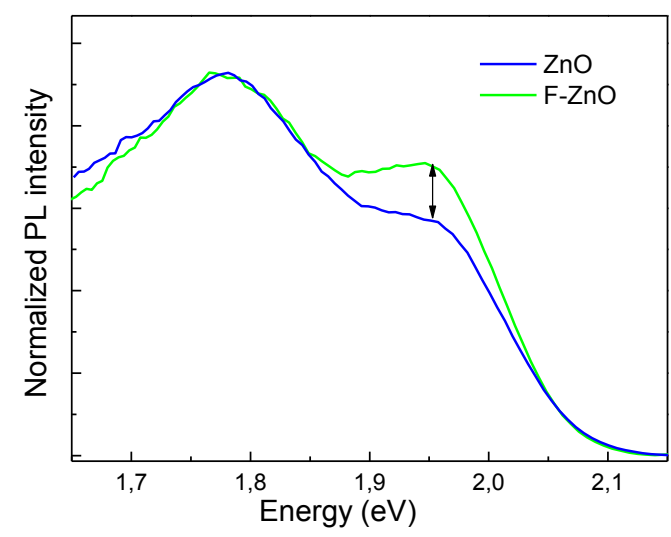

(d)

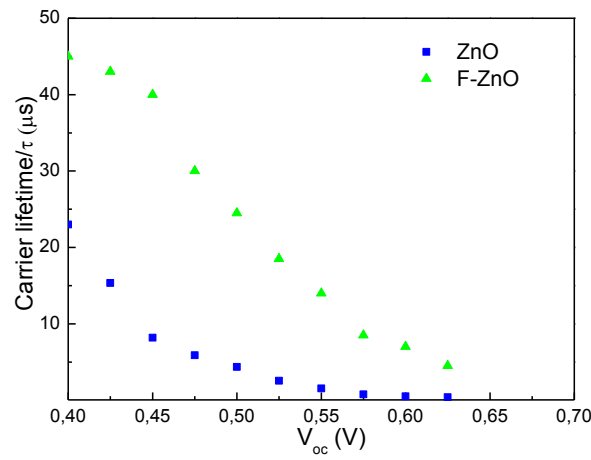

(b)

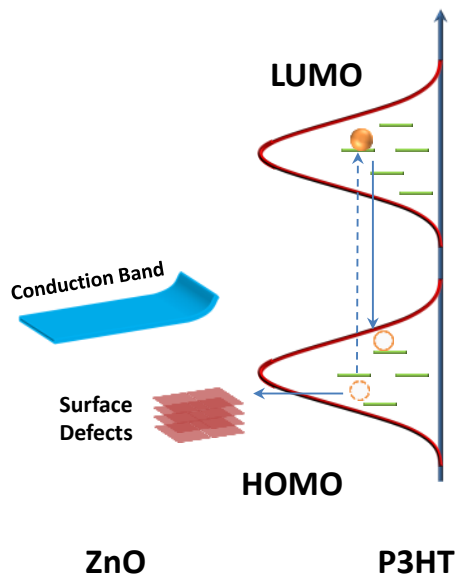

(e)

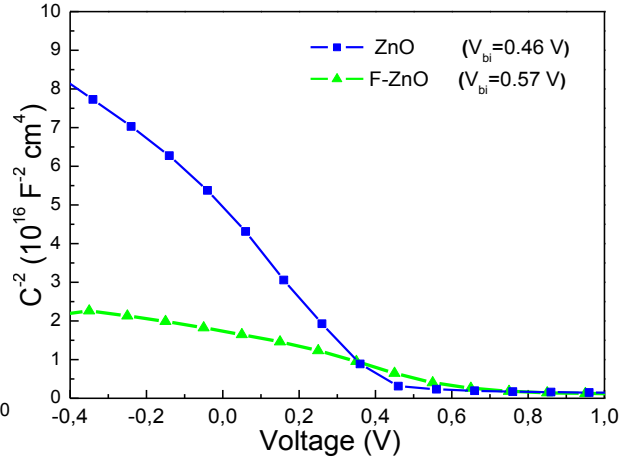

(c)

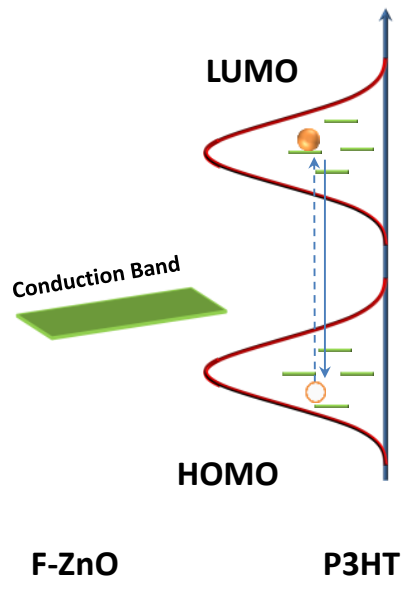

(f)

Figure 7 


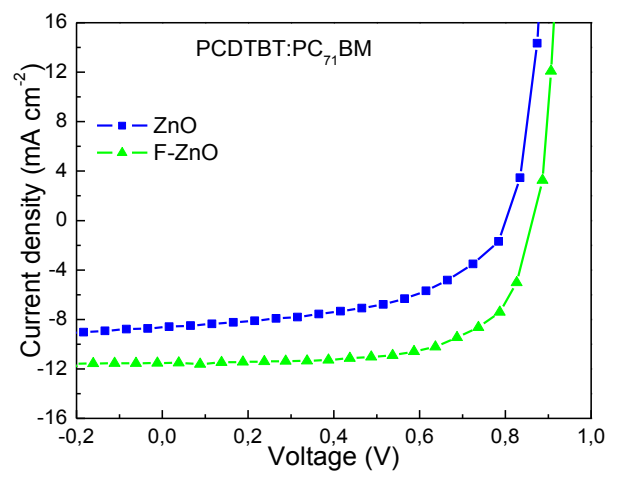

(a)

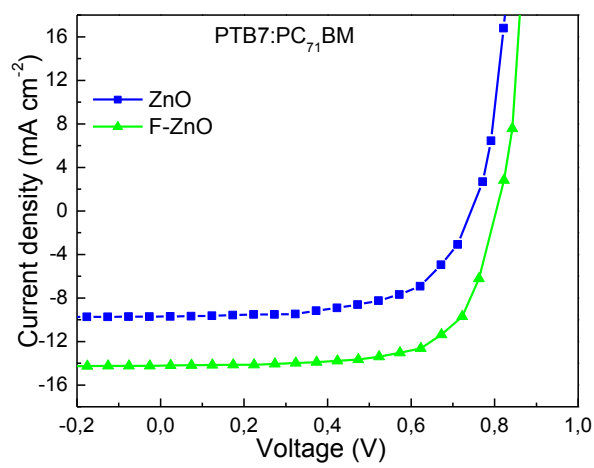

(d)

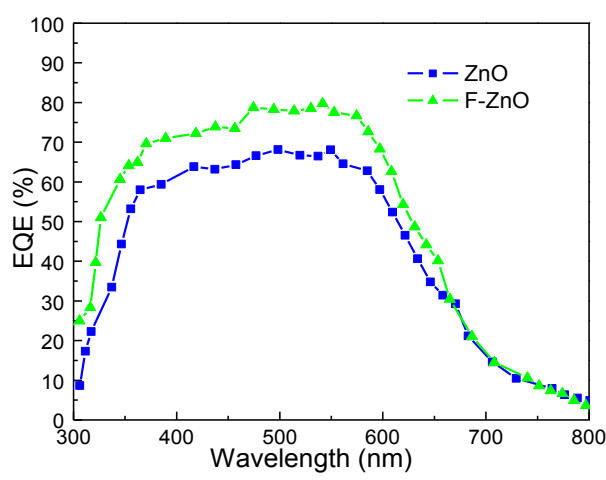

(b)

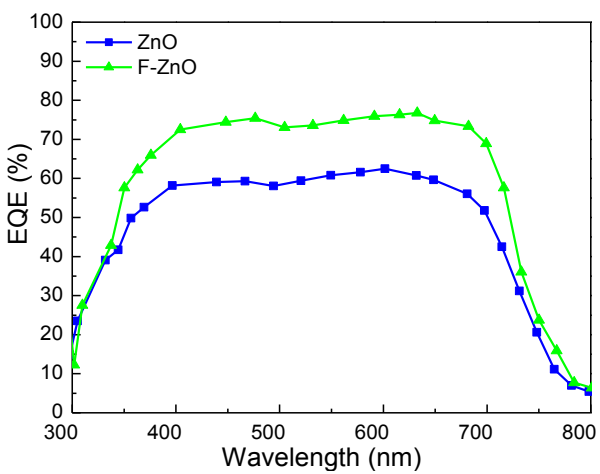

(e)

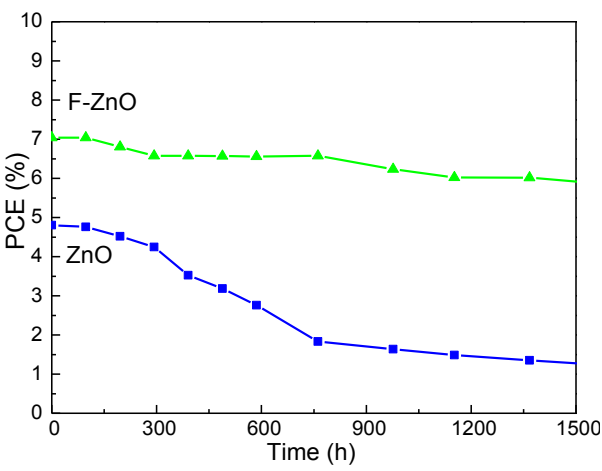

(c)

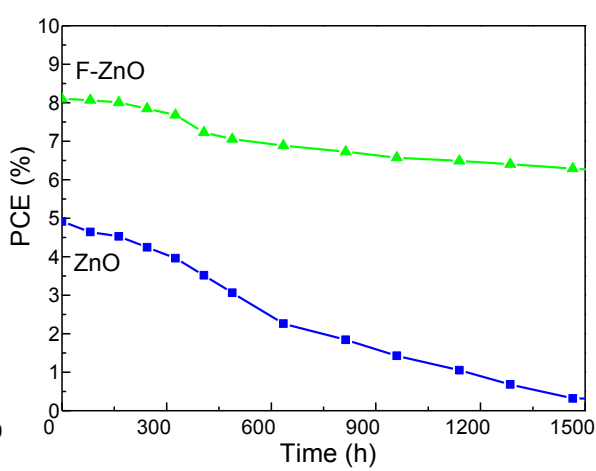

(f)

Figure 8 


\section{Table of Content}

The surface passivation effect of $\mathrm{SF}_{6}$ plasma on $\mathrm{ZnO}$ films for application in polymer solar cells is demonstrated.

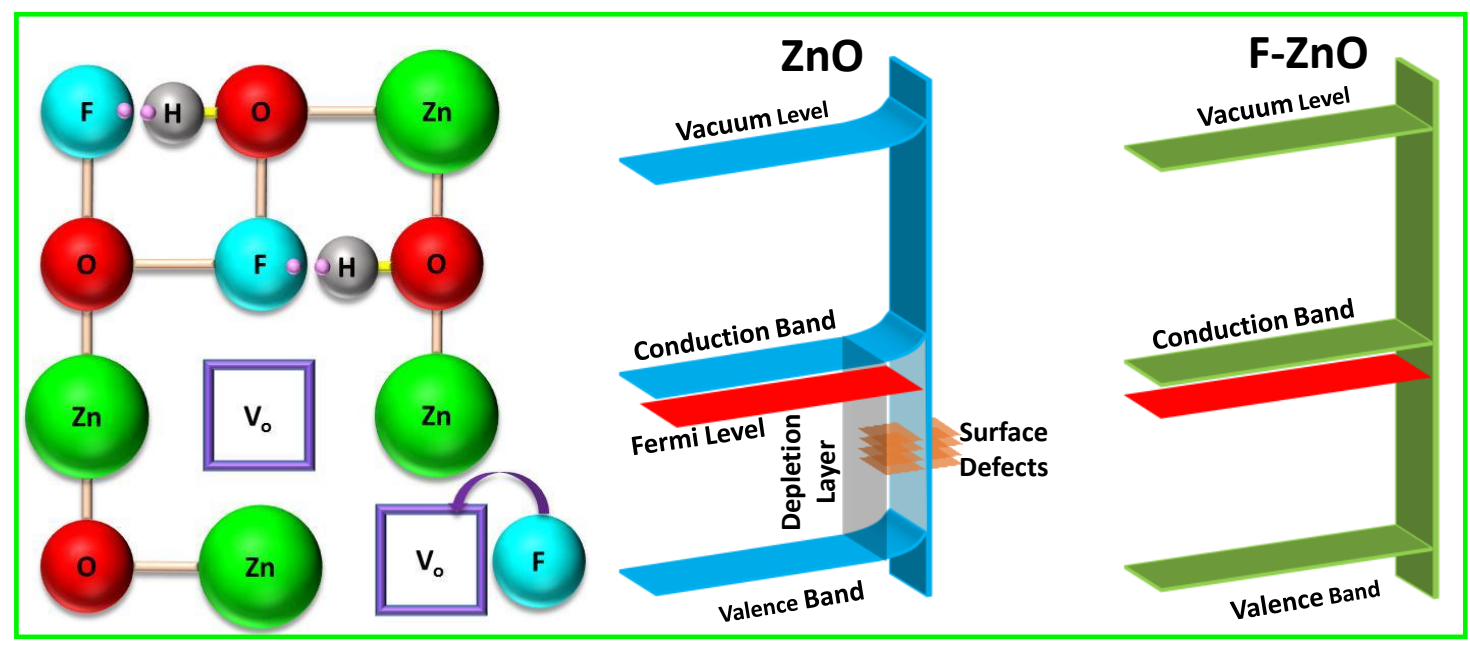

